\title{
"La parte alta del cerro es para los pequeños mineros". Sobre la vigencia del régimen minero especial para Marmato y su influencia en la construcción de territorialidad**
}

\section{"The top of the hill is for small miners". On the validity of the special regime for Marmato mining and its influence on the construction of territoriality}

SUMARIO

Introducción. I. Hacia la conformación del régimen especial para las minas de Marmato. 1. 1825-1925: de los inicios de la República a los tiempos de Alfredo Vásquez Cobo. 2. 1925-1954: el reparto del cerro de Marmato como una fórmula para conciliar el interés en la explotación eficiente con la pervivencia de la minería tradicional. II. Pervivencia del régimen especial para Marmato en la legislación posterior y su influencia en la construcción de territorialidad e identidad de sus habitantes. 1. 1980-2000: "Del socavón

* Abogada de la Universidad de Antioquia (1998), Ph.D en Derecho de la Universidad de Castilla-La Mancha (2005) y magíster en Antropología de la Universidad de Antioquia (2010). Ph.D. Student and Graduate Teaching Assistant, Department of History, Florida International University. Investigadora asociada al grupo Justicia y Conflicto de la Universidad Eafit. Contacto: glope161@fiu.edu

** Recibido el: 11 de mayo de 2015, aprobado el: 12 de octubre de 2015.

Para citar el artículo: G. P. LOPERA MESA, "La parte alta del cerro es para los pequeños mineros". Sobre la vigencia del régimen minero especial para Marmato y su influencia en la construcción de territorialidad, Derecho del Estado n. ${ }^{\circ}$ 35, Universidad Externado de Colombia, julio-diciembre de 2015, pp. 101-150. DOI: http://dx.doi.org/10.18601/01229893.n35.05

Este trabajo es un resultado parcial del proyecto de investigación "La consulta previa como herramienta para la transformación de contextos de desarrollo y la mitigación de conflictos socioambientales" (Código Colciencias 111552128789), desarrollado conjuntamente por los grupos de investigación RERDSA, del Instituto de Estudios Regionales de la Universidad de Antioquia, y Justicia y Conflicto, adscrito a la Escuela de Derecho de la Universidad Eafit. Agradezco de manera especial a esta última institución, por concederme el semestre sabático durante el cual pude efectuar el trabajo de campo y la búsqueda en archivos que sirven de soporte a este trabajo. 
al expediente”. De la administración directa a una ordenación cada vez más remota, mediata y uniforme de las minas de Marmato. 2. 2001-2015: ¿queda un lugar para la pequeña minería? 3. En definitiva, ¿qué queda del régimen especial para Marmato? 4. Territorialidad vertical como condición para un orden social y económico (algo) menos vertical. Conclusiones.

\section{RESUMEN}

Este artículo examina las circunstancias que motivaron la expedición de un régimen especial para las minas de Marmato a mediados del siglo XX, el cual reserva la parte alta del cerro para el ejercicio de la pequeña minería. Asimismo, explora la vigencia de dichas normas y la manera en que ellas han influido la construcción de territorialidad y el desarrollo de una forma de vida en torno al ejercicio de la pequeña minería tradicional.

\section{PALABRAS CLAVE}

Legislación minera, Marmato, pequeña minería, territorialidad, conflicto socioambiental.

\section{ABSTRACT}

This article examines the circumstances that led to the issuance of a special regime for Marmato mines in the mid-twentieth century, which reserves the top of the hill for the small-scale mining exploitation. It also explores the validity of these rules and how they have influenced the social construction of territoriality and a way of life developed around the traditional practice of small mining.

\section{KEYWORDS}

Mining legislation, Marmato, small-scale mining, territoriality, social and environmental conflict.

“Ocho días después, la población minera se agolpaba en la plazoleta y los callejones centrales, pasada la hora del meridiano. La noticia de que venían a tomar posesión de las minas, despojando a dueños y arrendatarios, cundió por toda la región como viento malo. De los contornos, de las cuchillas, de la hoya, de los apartados breñales llegaban gentes atraídas por aquel acontecimiento inaudito, sin precedentes en la 
historia comarcana, que amenazaba con perturbar la paz de tantas gentes laboriosas y desorientar muchas vidas. Mineros de Echendía y Marmato, apacibles pueblerinos de San Juan, moradores de la vega supiana, vecinos de Riosucio, la sede de la provincia; y toda la foránea gente traficante, interesada y curiosa, que allí plantaba su tienda de negocio". Gregorio Sánchez Gómez, La Bruja de las Minas (1938), 2010: 50.

\section{INTRODUCCIÓN}

El auge de las industrias extractivas en las dos últimas décadas ha incrementado el número y la intensidad de los conflictos socioambientales. En el caso de grandes proyectos de minería aurífera que pretenden ser desarrollados en zonas con vocación agrícola o forestal, tales conflictos suelen girar en torno a la aceptación o rechazo de la minería, enfrentando a quienes se rehúsan a que la tierra que cultivan y, con ella, su identidad campesina y su riqueza hídrica, forestal y paisajística, sea removida para ir en pos de las riquezas que yacen en el subsuelo, y quienes, por el contrario, sostienen que el desarrollo vendrá con la extracción de dichas riquezas. Entretanto, la llegada de este tipo de iniciativas a zonas con una larga tradición minera suele enfrentar a las empresas transnacionales, que se proponen adelantar proyectos a gran escala, con poblaciones locales que han construido su forma de vida en torno al ejercicio de la minería tradicional. En este último caso el debate no enfrenta a partidarios y detractores de extraer el oro, sino que gira alrededor de cuestiones tales como: ¿quién tiene derecho a extraerlo?, ¿cómo y a qué escala ha de llevarse a cabo su explotación?

Uno de los lugares de Colombia en donde se escenifica este segundo tipo de conflicto es el municipio de Marmato, una población multiétnica donde conviven 8.848 habitantes $^{1}$, situada en el noroccidente del departamento de Caldas, en el flanco este de la cordillera occidental y en la vertiente occidental del río Cauca. La cabecera municipal se localiza en la parte superior de un cerro hoy conocido como El Burro (antes denominado Cerro El Guamo o Marmato), al cual se llega a través de una serpenteada vía ascendente que se encuentra en la margen derecha de la carretera que comunica a Medellín con Manizales. La vía está pavimentada hasta un sector conocido como El Llano, tradicional asentamiento de población afrodescendiente, distante 3 $\mathrm{km}$ de la cabecera municipal, hoy convertido en zona de expansión y posible lugar para el reasentamiento de quienes habitan en la parte alta del cerro; esto

1 Según las cifras del último censo de población, el 56.5\% de los marmateños se reconoce como afrodescendiente y el 16.7\% como indígena (DANE, 2005). 
último en el evento de que llegue a ejecutarse el proyecto de gran minería a cielo abierto que una multinacional canadiense pretende adelantar en Marmato. Aunque existen yacimientos mineros en otras zonas del municipio, la mayor parte de las minas de las que los marmateños derivan su sustento se concentra en la parte alta del cerro El Burro, en el sector aledaño de Cien Pesos y en la vereda Echandía.

Durante el trabajo de campo adelantado en Marmato en el primer semestre de 2012, con el fin de efectuar un estudio de caso sobre los mecanismos de participación empleados por los habitantes del municipio para incidir en las decisiones relativas al proyecto de gran minería, los integrantes del equipo de investigación encontramos un argumento recurrente en algunos de los marmateños con quienes tuvimos ocasión de conversar: "si la empresa quiere desarrollar su proyecto, que lo haga en la zona baja, pero que nos deje tranquilos viviendo de la minería tradicional en la parte alta del cerro". Cuando indagamos por las razones para oponerse a que la empresa se instale en la zona alta del cerro y en cambio estar dispuestos a admitir su presencia en la zona baja, la respuesta común -además del desacuerdo con el inevitable traslado del municipio que supondría una explotación a gran escala en la parte superior del cerro- era que "ellos no pueden venir a ocupar la parte alta del cerro, porque está reservada para la pequeña minería". Todos coincidían en respaldar esta aseveración en un decreto expedido por Rojas Pinilla en 1954, que dividió el territorio entre una zona alta A, destinada a la pequeña minería, y una zona baja B, para la mediana minería. Aunque no logramos hallar en Marmato una copia del decreto, todos hablaban de él con gran propiedad, esgrimiéndolo como una valiosa herramienta legal para oponerse a la pretensión de la compañía de hacerse con la explotación de todo el cerro.

La pregunta que en principio me formulé, en mi condición de abogada integrante del equipo de investigación, era si el Decreto 2223 de 1954 -en el que los marmateños cifran buena parte de la confianza en que no solo la justicia sino también la ley está de su parte en el pulso que libran con la multinacional- efectivamente mantiene su vigencia o si, por el contrario, había sido derogado de manera expresa o tácita por alguna de las sucesivas reformas que la legislación minera ha tenido desde entonces. De la mano de esta cuestión inicial surgió la pregunta por las razones que en su momento justificaron la expedición de las normas que ordenaron esta distribución del territorio y cómo ellas han estructurado la manera en que los habitantes del municipio, incluidos indígenas y afrodescendientes, han construido su relación con el territorio y desarrollado una forma de vida en torno al ejercicio de la pequeña minería tradicional.

Con el fin de dar respuesta a estos interrogantes, este trabajo se divide en dos partes. En la primera se propone un recuento de la normatividad que, 
desde el comienzo de la República, incluyó a Marmato dentro de las minas de reserva especial de la nación, lo que significó excluir a los lugareños del derecho a denunciarlas y explotarlas, favoreciendo así el monopolio de las empresas inglesas a las que el gobierno cedió su explotación entre 1825 y 1925. A continuación se analiza la legislación especial expedida entre 1925 y 1954, mediante la cual se efectúa una división del cerro de Marmato en zona alta y baja, destinadas a la explotación de pequeña y mediana minería, respectivamente. Se propone como hipótesis que la adopción de este modelo de distribución del territorio y de los derechos de explotación sobre el oro se justificó (y tal vez estuvo motivado) por la necesidad de procurar una explotación eficiente de las minas y a la vez asegurar un espacio a los marmateños para el ejercicio de la pequeña minería; esto último como respuesta a las graves consecuencias sociales y económicas a las que condujo el régimen de monopolio, en especial durante el predominio del general Alfredo Vásquez Cobo.

En la segunda parte se examina la manera en que este modelo de reparto territorial se mantuvo en la legislación posterior y cómo en la actualidad continúa estructurando la relación de los marmateños con su territorio, preservando un espacio para el ejercicio de la minería tradicional a pequeña escala, en torno de la cual la población del municipio ha forjado su identidad y su cultura, así como las reglas de convivencia que rigen su relación con los foráneos que quieren venir a explotar sus recursos. Asimismo, se analizan los embates que en la última década ha tenido este modelo, como consecuencia de transformaciones legislativas y decisiones administrativas que han allanado el camino para la ejecución de un proyecto de gran minería en el municipio.

\section{HACIA LA CONFORMACIÓN DEL RÉGIMEN ESPECIAL PARA LAS MINAS DE MARMATO}

Aunque para los propósitos de este trabajo interesa fijar como punto de partida el comienzo del período republicano, es preciso volver la mirada unos siglos atrás para comprender de qué manera la historia de Marmato, al igual que la de los demás municipios que se asientan en la otrora denominada provincia de Anserma, ha estado desde sus inicios estrechamente vinculada al desarrollo de la minería ${ }^{2}$.

2 La antigua provincia de Anserma fue nombrada así por JORGE ROBLEDo para designar los territorios habitados por las diversas tribus que conformaban el pueblo Umbra o Anserma. Esta región, situada en la vertiente este de la Cordillera Occidental se extendía, por el norte, desde el Cerro de Caramanta hasta el punto donde el río Arquía desemboca en el Cauca; por el oriente, a lo largo del río Cauca hasta la desembocadura del río Cañaveral; por el sur, la frontera la traza el cauce del río Cañaveral (actual límite entre los departamentos de Risaralda y Valle), desde su nacimiento en el cerro Tatamá hasta su desembocadura en el Cauca; por el occidente, 
La gran riqueza aurífera del territorio Anserma llamó la atención de los conquistadores españoles, que pronto tomarían el control de la región con la fundación de Santa Ana de los Caballeros (actual Anserma Viejo) en 1539 y de varios reales de minas pocos años después, entre los que se destacan los de Quiebralomo y Marmato. El dramático descenso de la población indígena motivó la importación de cuadrillas de esclavos que, desde mediados del siglo XVI, fueron empleados como mano de obra en las minas ${ }^{3}$. Tras una importante crisis en la producción que se extendió durante buena parte del siglo XVII, el modelo inicial de explotación instaurado por los españoles, basado en la encomienda, paulatinamente dio paso a la hacienda minera; institución que se consolidó en el siglo XVIII dando lugar a la concentración en manos de una pequeña élite local de la propiedad de tierras, minas y esclavos. Aún hoy se conservan en la memoria de los habitantes de Marmato y Supía, así como en los apellidos de muchos de ellos, nombres como los de Domingo Echandía (dueño de las tierras y minas situadas en una conocida vereda al norte de Marmato que hoy lleva su apellido), don Agustín de Castro y Sebastián Moreno de la Cruz; los descendientes de estos dos últimos señores, que emparentaron por el matrimonio de dos de sus hijos, formaron una alianza familiar que tuvo el control de las minas de Marmato y Supía hasta finales del siglo XVIII, cuando pasaron a manos de la Real Compañía Minera de la Vega de Supía, que las explotó hasta cuando fueron expropiadas por el recién instalado gobierno republicano (González Escobar, 2002: 40-46; González Colonia, 2012: I, 2).

Esta tradición de monopolio sobre las minas por parte de encomenderos y hacendados no impidió que florecieran prácticas como el mazamorreo o el lavado de las arenas sobrantes de la explotación, que incluso resultan especialmente significativas desde el punto de vista histórico pues a través de ellas muchos de los esclavos de la región obtuvieron el oro suficiente para comprar su libertad (Boussingault, 1994: 107; Gärtner, 2005: 85). Pero en términos generales cabe afirmar que, salvo estos ejercicios marginales de minería a pequeña escala por parte de la población local, durante la Colonia el derecho de explotación se concentró en manos de españoles y de sus descendientes criollos.

entre la línea imaginaria que parte del Cerro de Caramanta y se extiende hacia el sur hasta el Cerro Tatamá (Abad Salazar, 1955: 22-23).

3 Según los datos que presenta RoBerT WeSt, para 1627 el Real de Minas de Quiebralomo ocupaba 110 esclavos negros y 20 indios, el de Marmato 70 esclavos negros, en La Montaña se registraban 40 indios y en las Vegas de Supía 51 esclavos negros y 80 indios (West, 1972: 20). 


\section{1825-1925: de los inicios de la República a los tiempos de Alfredo Vásquez Cobo}

Tal concentración se mantuvo tras el inicio de la república con la inclusión de las minas de Marmato dentro de las llamadas "minas de reserva especial", lo que suponía excluir a la población local del derecho a denunciar y explotar las minas que se hallaran en su territorio. Como explica José Luis Aramburo, con esta figura se designaba a un conjunto de propiedades mineras específicamente delimitadas, que constituían bienes fiscales del Estado, y dentro de ella quedaron comprendidas las minas de esmeraldas de Muzo y Coscuez, las salinas de Zipaquirá y Nemocón, las minas de plata de Santa Ana y La Manta en el municipio de Falán, las carboneras de San Jorge y Llano de Ánimas en el municipio de Suesca y las minas de oro y plata de Marmato en el departamento de Caldas (Aramburo Restrepo, 1980: 200) .

La razón que llevó a incluir a Marmato dentro de este selecto grupo está estrechamente vinculada al nacimiento de la república. Como herencia de la Colonia, desde el comienzo de la vida republicana ha regido en Colombia un sistema regalista de la propiedad minera, según el cual el Estado es propietario de las minas. Hasta 1858 se estableció que, si bien todas las minas pertenecían a la Nación, los particulares podían explotarlas mediante el sistema de adjudicación, a excepción de las minas de esmeraldas que solo podían ser explotadas directamente por el Estado. Durante el régimen federal establecido en las constituciones de 1858 y 1863 se concedió autonomía a cada Estado miembro para legislar sobre sus minas, con excepción de las de esmeraldas y sal gema que la Nación se reservaba para sí; por consiguiente, durante este período no existió un criterio único en relación con las minas de oro. A partir del régimen centralista reimplantado con la Constitución de 1886 se establece

4 Las minas de reserva especial del Estado estaban sustraídas del régimen ordinario de titulación minera, que hasta 1969 se hizo a través del sistema de adjudicación. La ley 20 de 1969 elimina el sistema de adjudicación para establecer como vías de acceso al derecho a explotar los sistemas de concesión, aporte y permiso. Esta misma ley establece, en su artículo $8 .^{\circ}$, que "los yacimientos que constituyan la reserva especial del Estado sólo podrán aportarse o concederse a empresas comerciales e industriales de la Nación o a sociedades de economía mixta que tengan una participación oficial mínima del 51\% del respectivo capital". Aunque en la actual legislación se abandona por completo el modelo de participación del Estado en la explotación minera, se mantiene un tratamiento especial para (algunas de) estas antiguas zonas de reserva especial; así, el artículo 356 de la Ley 685 de 2001 mantiene la vigencia de los contratos suscritos en las antiguas Minas de la Reserva Especial. No debe confundirse estas Minas de Reserva Especial con la figura de las Reservas Especiales contemplada en el artículo 31 del actual Código de Minas. Las áreas de reserva especial declaradas al amparo de esta última norma pueden consultarse en: http://www.minminas.gov.co/minminas/minas.jsp?cargaHome=3\&id_categoria=165, consultada el 23 de junio de 2012. 
que las minas de oro pertenecen a la Nación ${ }^{5}$, quien podrá adjudicar el derecho a explotarlas a los particulares que denuncien su existencia (Cardona, 1939).

Sin embargo, las minas de Marmato, así como otras ubicadas en el antiguo Cantón de Supía, se sustrajeron del régimen minero ordinario porque fueron entregadas en arrendamiento para cubrir los préstamos contraídos con casas banqueras inglesas para sufragar el costo de la guerra de independencia y del establecimiento de la naciente república ${ }^{6}$. Para entonces, el gobierno obtuvo un empréstito respaldado en la firma de un contrato el 18 de abril de 1825 con la casa B.A. Goldschmidt de Londres, en virtud del cual esta tomaría en arriendo, por un término inicial de 25 años, las minas de oro de la Vega de Supía y de Marmato, la salina del Peñol en Supía, así como otras minas en la provincia de Antioquia ${ }^{7}$. Ese mismo año, y antes de que las minas le fueran entregadas a la B.A. Goldschmidt, otra compañía inglesa, la casa Powles, Illington \& Cía., a través de su filial Colombian Mining Association, negoció directamente con los antiguos propietarios la compra de las mejores minas del Cantón, para lo cual contó con los servicios del mineralogista francés Juan Bautista Boussingault. Debido a esta movida, la casa Goldschmidt solo alcanzó a reclamar las minas menos productivas, lo que a la postre precipitaría su bancarrota y la llevaría a ceder los derechos adquiridos en virtud del contrato de arrendamiento a su poderosa competidora, la casa Powles, Illington \& Cía. Esta sucesión de arrendamientos y ventas sobre las minas dio lugar a interminables pleitos entre el gobierno colombiano y las compañías extranjeras que hicieron presencia en la zona, así como entre estas y los particulares de la región que alegaban tener derechos sobre algunas de estas minas (Morales Benítez, 1993; González Escobar, 2002: 56-66; Gärtner, 2005: 157-160, 193 196, 308; González Colonia, 2012: I, 11).

5 Tanto por disposición expresa del artículo 202 de la Constitución como porque a través de la Ley 38 de 1887 se adopta para toda la Nación el Código de Minas del extinto Estado Soberano de Antioquia que así lo establecía.

6 La primera división política de la naciente república, acordada en el Congreso de Cúcuta en 1821, constaba de 7 departamentos, cada uno de los cuales estaba repartido en provincias que, a su vez, estaban conformadas por cantones. Entre los cantones de la Provincia de Popayán se encontraba el de Supía, que agrupaba los pueblos de la Vega de Supía, Riosucio (para entonces denominado La Unión de Quiebralomo y La Montaña), Ansermaviejo, Quinchía, Guática, Tachigüí, Tabuyo y el mineral del Marmato (GÄRTNER, 2005: 143).

7 Según explica Álvaro GäRTNER, en virtud de este contrato la casa Goldschmidt se obligaba a pagar a la República de Colombia el 5\% anual sobre el valor de tierras, edificios e instalaciones mineras; el $8 \%$ del producto líquido, además de los derechos de quintos y fundición, así como 2.000 patacones de oro anuales, a cambio del derecho a extraer oro y plata durante 25 años forzosos y 50 voluntarios. Entretanto, el gobierno se obligaba a dar en arrendamiento todas las minas pertenecientes al gobierno y las que sus antiguos dueños hubieran abandonado. Asimismo, para honrar el cumplimiento de este contrato, el gobierno prohibió a los particulares denunciar minas en el territorio del Cantón de Supía (GÄRTNER, 2005: 155-156). 
Tales pleitos no alteraron la situación de monopolio de la explotación aurífera que durante buena parte del siglo XIX ejerció la casa Powles, Illington \& Cía., a través de su filial la Colombian Mining Association. Monopolio ratificado por el gobierno colombiano, mediante la Resolución del 1 de diciembre de 1832, en la que incluyó todas las minas de la Vega de Supía y de Marmato, que para el 18 de abril de 1825 se estaban beneficiando de cuenta de la república, o estaban descubiertas y no habían sido enajenadas por ella, dentro del contrato de arrendamiento celebrado con la casa B.A. Goldschmidt o sus cesionarios. Esto implicaba poner en riesgo los derechos de quienes venían ejerciendo labores de explotación de hecho o habían adquirido minas antes de la celebración de dicho contrato, dado que no se determinaban los linderos de las minas dadas en arriendo. Por otra parte, dicha resolución prohibía a los particulares denunciar dichas minas, así no estuvieran siendo beneficiadas por los arrendatarios. Según explica Álvaro Gärtner, "con esta resolución, el Gobierno colombiano renunció de hecho a su soberanía en Marmato, pues la norma relevaba a los ingleses de cumplir con la razón de ser de su presencia allí, como era la explotación de las minas, protegiéndolos en su inactividad al impedir que otros pudieran trabajarlas" (Gärtner, 2005: 198).

En 1853 la Colombian Mining Association se transformó en la Mariquita and New Granada Mining Company, también controlada por la casa Powles, Illington \& Cía. En 1872 esta compañía fue despojada de su posición dominante, al perder un juicio interpuesto por otro ciudadano inglés, Percy Brandon, quien pasó a sustituir a la Mariquita and New Granada en el contrato de arrendamiento de las minas de la nación. Al año siguiente, Brandon cedió sus derechos a The Western Andes Mining Company, que mantendría su posición dominante en la región hasta comienzos del siglo XX (González Escobar, 2002: 66, 187-190; Gärtner, 2005: 310).

Con todo, ya en el tercio final del siglo XIX la capacidad de las compañías inglesas para controlar y explotar la amplia zona minera concedida en arriendo parecía llegar a su fin, al tiempo que comenzaban a proliferar sociedades mineras constituidas por miembros de las élites locales. En un primer ciclo, la actividad de estas nuevas sociedades se orientó al beneficio de los minerales, particularmente en la amalgamación de la plata, pero poco tiempo después se expandiría hacia el descubrimiento y montaje de nuevas minas ${ }^{8}$. Esto último

8 Gracias al juicioso trabajo de archivo que respalda su investigación, LUIS FERNANDO GONZÁLEZ EsCOBAR documenta la existencia de 66 títulos mineros refrendados o expedidos hasta 1883 por el Estado Soberano del Cauca (la mayoría de ellos localizados en Riosucio, Supía y Marmato), así como la constitución de 18 sociedades mineras en el período 1867-1877, de 30 entre 1879 y 1884 , y de 15 más entre 1887 y 1900 . Entre los socios figuran conocidos nombres de la élite local como Celestino de la Roche, Rudecindo Ospina, José de Jesús Hernández, Bartolomé Chávez, Luis Horacio Zavala, Francisco Senén Tascón, Vicente de la Cuesta, Santiago 
como consecuencia de la Ley 59 de 1873, del Estado Soberano del Cauca, donde se estableció que en lo sucesivo no sería necesario el denuncio de minas y que el dueño del terreno sería dueño de las minas no denunciadas ni tituladas. A ello se sumó, en los dos años siguientes, la disolución del resguardo indígena de Supía y Cañamomo, lo que desembocó en la adjudicación de buena parte de sus tierras a empresarios locales, pero también a nativos y colonos, algunos de los cuales entraron a participar de las nacientes sociedades mineras aportando, a cambio de acciones, los terrenos que recién les habían adjudicado. Como señala Luis Fernando González, esta dinámica, amparada por la legislación caucana (que fue impulsada principalmente por las élites locales), posibilitó una suerte de "democratización" de las sociedades y, a su vez, del derecho de explotación sobre las minas de la zona, marcando así un contrapunto frente a la tendencia a su monopolio favorecida por las leyes nacionales que establecieron el régimen especial para las minas de Marmato (González Escobar, 2002: 210-212).

De estas disputas entre mineros locales y la empresa que reclamaba el monopolio para explotar las minas de la zona da cuenta la queja elevada en 1887 por el gobernador del Cauca ante el Ministro de Fomento, acusando el abandono en que permanecían muchas de las minas dadas en arriendo a la Western Andes Mining, pese a lo cual,

... cuando los vecinos del antiguo Cantón de Supía tratan de hacer a los alrededores de ellas algún descubrimiento de oro o plata que por allí tanto abundan, al instante la compañía arrendataria se opone decididamente y con el acomodo de una información de dos o tres testigos, quizás interesados o sin el suficiente conocimiento de los hechos sobre que deponen, reclama y es atendida al instante por las autoridades superiores, sin dar siquiera audiencia a los individuos contra quienes la querella versa (citado por Gärtner, 2005: 368).

Haciendo caso omiso de las protestas de las autoridades locales, y en oposición a las normas expedidas por el gobierno caucano en la década anterior, el artículo 6. ${ }^{\circ}$ de la Ley 38 de 1887 (mediante la cual se adoptó a nivel nacional el Código de Minas del antiguo estado de Antioquia), ratificó el régimen especial al que estaban sometidas estas y otras minas que habían sido comprometidas con los ingleses para pagar el precio de la independencia, al señalar que "no podrán denunciarse ni en todo ni en parte las minas de oro y de plata que se han explotado por cuenta de la Nación en Marmato, Supía y Santa Ana, ni las tierras baldías comprendidas dentro de sus límites".

Silva, Ramón y Miguel y Gonzalo Palau, Julio Richter y Tomás Eatsman (GonZÁLEz EsCOBAR, 2002: 206-245, 487-506). 
Pero esta prohibición no bastó para evitar la crisis en que se hallaba la Western Andes para finales del siglo XIX, debida, entre otros factores, al agotamiento de los yacimientos, el poco rendimiento de los métodos de beneficio, la inestabilidad política y los pleitos legales en torno a la propiedad de las minas. Pleitos que se agudizaron tanto por la expedición de la ya mencionada Ley 59 de 1873 como por la impugnación formulada en 1881 por el gobierno caucano en contra de la constitucionalidad del contrato de arrendamiento suscrito en 1825, argumentando que las minas pertenecían al Estado del Cauca y no a la Nación, por lo que esta no tenía facultades para entregarlas en arriendo a extranjeros (Gärtner, 2005: 367). Tal cúmulo de circunstancias motivó a la compañía inglesa a buscar un cesionario de sus derechos sobre las minas, encontrando el "cliente perfecto" en la sociedad antioqueña Ospina Hermanos, que en 1891 suscribió con la compañía inglesa un contrato de arrendamiento sobre parte de las minas. Ante las dificultades que encontraron los Ospina para extraer el mineral y cumplir con las obligaciones del contrato, optaron por ayudar a la Western Andes a encontrar un comprador para todas sus minas y así lograr rescindir el contrato de arrendamiento. Sin embargo, las irregularidades de esta fallida negociación dieron lugar a una larga estela de pleitos judiciales, a la suspensión de trabajos en las minas y a una crisis social en Marmato ante la cantidad de trabajadores mineros que quedaron cesantes (Gärtner, 2005: 375-388). A esta crisis vino a sumarse el estallido de la Guerra de los Mil Días, que marcaría el final de la hegemonía de la Western Andes en la región. El 10 de julio de 1905 esta compañía entregó a la Nación las minas que tenía a su cargo, a excepción de las de San Antonio, La Cruzada y el establecimiento minero de El Guamo o Marmato, afirmando que estas habían sido adquiridas en propiedad (González Escobar, 2002: 375; Gärtner, 2005: 412).

Esto no supuso el fin del monopolio sobre las minas del antiguo Cantón de Supía, sino tan solo el cambio del actor dominante. Amparado en las facultades del Estado de Sitio, ese mismo año el presidente Rafael Reyes expidió el Decreto Ley 48 de 1905, que prohibió a los particulares denunciar minas nuevas o continuaciones de las existentes, facultó al gobierno a apropiarse de las minas particulares en laboreo e impidió continuar trabajos en las minas reservadas por la Nación. En adelante, la administración de estas minas se haría a través de una Junta de Amortización encargada de arrendarlas sin sujeción a las disposiciones del Código Fiscal, lo que en la práctica permitió al nuevo gobierno servirse de ellas para compensar a sus aliados los favores recibidos durante la Guerra de los Mil Días. Fue así como el gobierno de Reyes confirió al general Alfredo Vásquez Cobo, quien comandó los ejércitos conservadores durante la guerra, poderes para reclamar a la Western Andes Mining tanto las minas que le fueron arrendadas como aquellas que los ingleses 
consideraban de su propiedad, al igual que las demás minas en la provincia de Marmato que estuvieran en manos de particulares. Las minas fueron entregadas en arrendamiento a Vásquez Cobo por un término de 20 años a través de contratos suscritos el 12 de mayo y el 16 de agosto de 1906, así como en virtud de sentencias de la Corte Suprema de Justicia del 7 de mayo y 25 de agosto de 1906, que ordenaron a la Western Andes entregar al apoderado de la Nación las minas que reclamaba como suyas (González Escobar, 2002: 375-377). Pero el poder político y militar que ostentaba el general, recién nombrado Ministro de Relaciones Exteriores, le permitió hacerse al control, no solo de estas sino de todas las minas de la provincia de Marmato. Vásquez Cobo entregaría estas minas en arriendo en 1907 a una compañía inglesa en la que tenía participación, The C. W. Syndicate Limited, la que, a su vez, las traspasaría al año siguiente a The Colombian Mining and Exploration Company Limited, de la que también era socio el general, lo que le permitió ejercer su poderío en la zona hasta 1926, cuando formalmente las minas revirtieron a la nación (González Escobar, 2002: 374-381; Gärtner, 2005: 427).

Investigadores de la región coinciden en señalar la profunda crisis social y económica en que quedaron sumidos Marmato y los municipios vecinos a consecuencia de las estrategias puestas en marcha por los hermanos Alfredo y Eduardo Vásquez Cobo para lograr el pleno control sobre la zona. Estrategias que incluyeron el despojo violento de sus medios de trabajo a mineros y mazamorreros de la zona, la destrucción y saqueo de propiedades, la compra de acciones en sociedades mineras locales hasta lograr hacerse al control sobre ellas, la persecución judicial a los empleados de la Western Andes, así como a otros empresarios locales como Joaquín Antonio Cruz, propietario de las minas de Echandía, a quien sobrevino la locura como consecuencia del acoso al que fue sometido por Vásquez Cobo en el intento de apoderarse de sus minas (Morales Benítez, 1993; González Escobar, 2002: 380-385; Gärtner, 2005: 421-426) ${ }^{9}$. También la literatura de la época ofrece un elocuente testimonio de estos hechos en la novela La Bruja de las Minas, escrita en 1938 por el

9 González Escobar señala que entre 1905 y 1930 desaparecieron la casi totalidad de las sociedades mineras que habían surgido en el último tercio del siglo XIX; las pocas que quedaron pasaron a ser controladas por Vásquez Cobo o las compañías inglesas que hacían presencia en la zona, mientras que la mayoría de los miembros del criollato local emigraron con su capital a otras zonas, luego de negociar o incluso abandonar sus tierras. Pero a la vez, este mismo autor sostiene que, en contraste con la decadencia económica y social de las zonas urbanas, durante el mismo período se asiste a una dinamización del mundo rural, como resultado de la ocupación de las tierras que fueron abandonadas por las sociedades mineras, así como de la fragmentación y desconcentración de la propiedad de la tierra que resultó de la liquidación de las antiguas sociedades (propietarias de grandes globos de tierras) y del incremento de las transacciones sobre estos predios. A la postre ello contribuyó a una transformación de la vocación económica en la región de la Vega de Supía, donde la agricultura (café y caña), la ganadería y la extracción de 
chocoano Gregorio Sánchez Gómez. En ella se relata el violento despojo de minas y tierras de que fueron objeto los habitantes de Marmato a manos de un ejército comandado por el general "Mandíbulas"; episodio que marcará la vida de algunos de los personajes que, como Aspasia, su protagonista, nunca lograron sobreponerse a la tragedia (Sánchez Gómez, 2010).

Luego de que el general Rafael Reyes, principal valedor de Vásquez Cobo, dejara la Presidencia en 1909, los habitantes de la provincia levantaron su voz tanto en la prensa local como ante el gobierno nacional para denunciar los desmanes de los que estaban siendo víctimas, como lo evidencia esta comunicación, enviada al general Rafael Uribe Uribe por el general marmateño Ramón Marín el 24 de abril de 1909 en donde anuncia:

Pensamos lebantar en toda la Probincia una petición pidiendo al que se aga el deslinde de las minas nacionales y las que no pertenesen a la nación y que de ese modo deje Basquez Escoba (Vásquez Cobo) trabajar y buscar a los abitantes de la probincia la vida pues como Ud sabe los abitantes de la probincia son todos mineros y no los adejado que aser (citado por Gärtner, 2005: 430) ${ }^{10}$.

Pocos meses después, en carta del 6 de octubre de 1909, Ramón Marín exhorta de nuevo al general Uribe Uribe a:

Ver si antes de clausurar las secciones del Congreso pueden hacer algo en favor de la industria minera de la Provincia de Marmato pues en ella estamos los habitantes en calidad de esclavos pues todavía domina el poder de Vásquez Cobo y no hay cañada donde un pobre trabajador quiera, buscando el pan de sus hijos que, allí no esté un tal Luis Cock imponiéndoles arrendamiento o de lo contrario son llevados por la policía y aún encarcelados... (citada por Morales Benítez, 1993).

Estas denuncias encontraron eco en el debate promovido en el Congreso en el año de 1909 por Carlos E. Restrepo, secundado por el marmateño Tomás Osciel Eatsman y el representante bogotano José Vicente Concha, que si bien no condujo a la sanción de Vásquez Cobo ni de los funcionarios que favorecieron sus tropelías, sí permitió dar a conocer en el plano nacional la

madera (para abastecer las minas de Marmato) desplazaron a la minería, actividad que en adelante se concentraría en Marmato (González Escobar, 2002: 394-401).

10 En la petición a la que se refiere Marín, respaldada por un importante número de firmas de mineros de la provincia y de personajes locales de reconocida prestancia, se solicitaba al Congreso: “a) devolver las minas reservadas por el Estado a los límites originales señalados en 1825, cuando la entrega a la primera compañía inglesa; b) obligar al Gobierno a pagar perjuicios causados a terceros por el laboreo de sus minas; c) investigar las denuncias y devolver 'a sus dueños los bienes que se les arrebataron, y ya que esto no sea posible que se les indemnice' $[\ldots]$ d) legitimar las adjudicaciones de baldíos" (Gärtner, 2005: 433). 
problemática social y económica en la que había quedado sumida la provincia de Marmato (Morales Benítez, 1993; Gärtner, 2005: 434-438).

\section{1925-1954: el reparto del cerro de Marmato como una fórmula para conciliar el interés en la explotación eficiente con la pervivencia de la minería tradicional}

En 1925, cuando estaba próximo el vencimiento del contrato de arrendamiento con la compañía inglesa a la que Vásquez Cobo había cedido sus derechos, Luis Salas y Ernesto Bueno Cock, representantes a la Cámara elegidos por la provincia, presentaron un proyecto para impedir la prórroga del contrato, que a la postre se convertiría en la Ley 38 de 1925, conocida en la región como la "Ley Salas"11. El mismo año se expidió la Ley 87 de 1925, en la que se ordena contratar un estudio geológico, jurídico y económico de las minas, pertenecientes a la república, conocidas con el nombre genérico de Supía y Marmato, con el fin de determinar, entre otros aspectos, sobre cuáles de estas minas el derecho de la Nación es indiscutible y en cuáles otras es disputado por terceros.

Con base en dicho informe, esta ley autoriza al gobierno para: (i) emprender las acciones judiciales necesarias para hacer efectivos los derechos de la Nación sobre estas minas y efectuar contratos de transacción orientados a solucionar los pleitos pendientes; (ii) celebrar un contrato de arrendamiento de dichas minas por 25 años (prescindiendo del trámite de la licitación pública si ello fuera menester para facilitar la resolución de pleitos pendientes en razón de contratos anteriores); (iii) decidir sobre la conveniencia de enajenar dichas propiedades, caso en el cual deberá informarlo al Congreso, para que este disponga lo que estime conveniente. La ley señala además que los contratos de transacción y arrendamiento estarán sometidos a autorización legislativa y, mientras se toma una decisión definitiva sobre arrendamiento o venta de las minas, se faculta al gobierno para proveer a la administración de dichas minas a través de contratos provisionales que no requieren aprobación legislativa, sino del Consejo de Ministros ${ }^{12}$.

11 En un informe presentado por la Comisión de la Cámara de Representantes encargada de verificar la situación de las minas de Marmato se hace un balance bastante crítico de esta ley, sugiriendo que Luis Salas, uno de sus promotores, participaba de una sociedad minera interesada en adueñarse de las minas de Marmato justo en el momento en que la compañía inglesa comenzaba a recoger los frutos de sus cuantiosas inversiones de capital (GÄRTNER DE LA CUESTA, Moreno Díaz y SAnín VilLa, 1936: 3265-3266).

12 Ley 87 de 1925, Diario Oficial 20057 del 25 de noviembre de 1925. 
Tras una serie de disputas jurídicas y negociaciones entre el gobierno y la compañía, finalmente las minas fueron devueltas a la Nación en 1926 a cambio del pago de una cuantiosa indemnización y de otras condiciones fijadas en un contrato que recibió aprobación del Congreso mediante la Ley 7 de 1930. Durante ese período las minas estuvieron en una parálisis casi absoluta, lo que agravó aún más la problemática socioeconómica en el municipio ${ }^{13}$.

Con el ánimo de reactivar la explotación, entre 1931 y 1940 se suscribieron sucesivos contratos de arrendamiento con empresarios nacionales sobre las minas de El Guamo o Cerro de Marmato: entre 1931 y 1935 fueron entregadas a Roberto Luis Restrepo y Alfredo Londoño; entre 1935 y 1938 a Manuel Uribe Afanador; entre julio de 1938 y marzo de 1940 a José Miguel Lizarralde. Ese año el gobierno asumió de nuevo la administración de estas minas, inicialmente por conducto de Hernán Garcés, director de la Planta Metalúrgica Nacional, pero al mes siguiente la misma pasó a depender directamente del Ministerio de Minas, quien nombró como administrador a Gustavo White (Gallego Estrada y Giraldo Rodas, s. f.; 120-121; González Escobar, 2005: 385; Tobón Rodríguez, 2000: 19).

Era evidente el afán del gobierno nacional por encontrar una fórmula que permitiera conciliar el interés en lograr una explotación eficiente de las minas, lo que para algunos hacía aconsejable entregar su explotación a una empresa sólida, capaz de generar los volúmenes de producción que alimentaran las arcas públicas ${ }^{14}$. Pero aún estaban abiertas las heridas que generó en la región el monopolio sobre las minas, que había llegado a su máxima y más agobiante

13 Las cifras presentadas en la Memoria del Ministro de Hacienda de 1930 ilustran de manera elocuente el declive de la rentas percibidas por la Nación por concepto de la explotación de las minas de Supía y Marmato (GÄRTNER, 2005: 453):

\begin{tabular}{|c|c|}
\hline Año & Valor de la renta \\
\hline 1923 & 16.000 \\
\hline 1924 & 16.000 \\
\hline 1925 & 9.333 \\
\hline 1926 & 0 \\
\hline 1927 & 0 \\
\hline 1928 & 416,17 \\
\hline 1929 & 0 \\
\hline
\end{tabular}

14 Afán que se expresa en el informe presentado en 1939 por el entonces Ministro de Economía, Jorge Gärtner, en el que criticaba el sistema de laboreo en participación previsto en el contrato de administración de las minas para entonces vigente: "Este sistema de laboreo en participación ofrece graves desventajas, y desde luego, si hubiera de persistirse en él, sería indispensable darle un desarrollo amplio, lo que no eximiría a la Nación de erogaciones cuantiosas tanto en orden a estudios rigurosos, suministro de equipo moderno para extracción, acarreo y beneficio, planta eléctrica y servicios comunes [...], como por lo atañedero a la dirección y vigilancia de los trabajos técnicos de explotación. Todo ello reafirma al Gobierno en la idea de que 
expresión durante los tiempos en que el general Vásquez Cobo mantuvo su hegemonía en la zona. Era preciso, por tanto, diseñar un modelo de explotación que evitara su concentración en un solo actor y abriera un espacio a los marmateños para buscar y explotar por su cuenta los recursos del cerro.

Las leyes de la época trataron de conciliar ambos intereses a partir de un modelo de explotación basado en la división del territorio de Marmato. Un primer paso en tal dirección se expresó en la Ley 72 de 1939 y su Decreto reglamentario 461 de 1940, expedida durante la presidencia de Eduardo Santos, siendo el riosuceño Jorge Gärtner su Ministro de Economía. Dicha ley, que en parte acoge las recomendaciones formuladas en el Informe presentado en 1936 por una Comisión de la Cámara de Representantes ${ }^{15}$, confiaba la administración y explotación de las minas de propiedad nacional conocidas como El Guamo o Cerro de Marmato y Cien Pesos, localizadas en el municipio de Marmato, a un Director General que tendría a su cargo la explotación directa de un conjunto de minas (las del grupo denominado La Palma) y dejaba en manos de los mineros locales la explotación de las minas restantes bajo la figura de pequeños contratos de laboreo en participación, bajo la supervisión de la Dirección de Minas ${ }^{16}$. Para tal efecto, el Decreto 461 de 1940 estableció los siguientes grupos de minas alrededor de los molinos existentes:

1. Grupo Norte Inferior: Molino El Infierno y minas Maruja, Zancudero, Verónica y Villonza, hasta el nivel del piso de la Gärtner, incluyendo todas las minas que estén dentro de los niveles de Maruja y la Gärtner.

2. Grupo Norte Superior: Molino Cien Pesos y minas Gärtner, Pompilia, las de la región de Cien Pesos, al norte de la quebrada Pantano, sobre la veta La Cubana o El Uno, y demás vetas que se descubran en dicha zona.

3. Grupo Sur Inferior: Molino San Antonio y las minas situadas por debajo del nivel del piso de la mina Caparrosal.

es preferible contratar el beneficio de las minas con una entidad capaz de respaldo financiero" (GÄRTNER, 1939: 89).

15 Esta Comisión, integrada por Carlos Gärtner de la Cuesta, Héctor Moreno Díaz y Gabriel Sanín Villa, no alcanzó una conclusión unánime sobre cuál debía ser el futuro de las minas de Marmato y Supía. Mientras los dos primeros recomendaban que una entidad de derecho público asumiera directamente la administración de las minas (modelo que efectivamente se acoge en la Ley 72 de 1939), Sanín Villa, en cambio, se mostraba partidario de entregarlas en concesión a una empresa privada, por considerar que el Estado no debía aventurarse en negocios de naturaleza aleatoria, como es el caso de la explotación de minas (GÄRTNER DE LA CUESTA, MORENO DíAZ y SANín VILLA, 1936: 3275-3276).

16 Contratos que al parecer comenzaron a implementarse poco tiempo atrás, cuando la nación reasumió el control de las minas (GÄRTNER, 1939: 89). 
4. Grupo Sur Superior: Molino El Colombiano y las minas entre los niveles de los pisos de Caparrosal y Puerquera.

5. Grupo Medio (Echandía): Minas Puerquera, Puerquera segundo piso, La Eva, San José, Tesorito, Torrentico, Torrente, La Escalera, a las que podrá añadirse una zona entre Echandía y la cañada Santa Inés. No incluye el Molino de Echandía por ser propiedad del señor George James Geale.

6. Las minas no incluidas podrán ser contratadas con sus poseedores y los minerales beneficiados en el molino Santa Cruz.

7. Grupo de La Palma: Las minas localizadas en el nivel del piso de la Maruja hacia abajo, en el sector norte inferior, serán explotadas directamente por la Dirección de las Minas, que instalará en La Palma una planta de beneficio y experimentación, que servirá de guía para orientar la explotación y beneficio en los demás sectores ${ }^{17}$.

Pocos años después, bajo la presidencia de Mariano Ospina Pérez, se expidió la Ley 66 de 1946, con la cual se abandonó la compleja zonificación establecida en la normatividad anterior para, en su lugar, sentar las bases de la actual división en dos zonas:

- Zona Alta A: Comprende todas las minas situadas por encima de la línea siguiente: partiendo del mojón n. $^{\circ} 4$ (confluencia de la quebrada o canalón de La Torre con la quebrada Pantano) se sigue en línea recta hasta la bocamina Villonza; de allí siguiendo por todo el camino que llega a la mina Villonza y pasando por el nivel piso bajo de la mina San Pedro, hasta llegar al empalme con la carretera de El Colombiano; de aquí siguiendo por toda la carretera hasta el punto que marca la intersección de los ejes de la carretera y de la tubería de presión del molino El Colombiano; de este punto en línea recta pasando por la bocamina 5000 hasta cortar la quebrada Cascabel y por esta aguas arriba hasta donde está reconocida la propiedad minera nacional.

- Zona Baja B: Incluye toda el área de las minas que están debajo de la línea descrita para la delimitación de la Zona Alta A. Hacia el norte el límite entre ambas zonas está dado por la curva de nivel que pasa por la confluencia del canalón de La Torre y la quebrada Pantanos.

17 La zona de explotación más avanzada para la época era la del sector de La Palma, donde The Colombian Mining and Exploration Company había realizado pocos años antes de devolver las minas una inversión en tecnología que fue calificada como "la más fuerte inversión que para el laboreo de minas de veta se haya hecho en este país, en un solo esfuerzo de capital" (GÄRTNER De la Cuesta, Moreno Díaz y Sanín Villa, 1936: 3263; GonZÁlez Escobar, 2002: 408), lo que explica la decisión de confiar su manejo a la Dirección de Minas y de instalar allí una planta piloto de beneficio y experimentación. 
La finalidad de esta división fue reservar la zona alta para el ejercicio de la pequeña minería, a través del sistema de pequeños contratos o permisos de explotación suscritos por el Director de Minas de Marmato, y entregar la zona baja a una o dos empresas encargadas de su explotación a mediana escala ${ }^{18}$. En esta nueva distribución se advierte el interés, por un lado, de posibilitar la coexistencia de dos escalas de explotación minera y, por otro, de conciliar la divergencia de criterios que para la época existían en torno a si la explotación de las minas debía estar a cargo del Estado o del capital privado (Gärtner de la Cuesta, Moreno Díaz y Sanín Villa, 1936: 3274-3276). Pero además de esta división territorial, se establecen una serie de reglas que han contribuido a configurar las relaciones productivas en el municipio, algunas de las cuales se mantienen vigentes, adaptadas a las condiciones actuales de la explotación, como ocurre con la que disponía el derecho de los pequeños contratistas sobre el oro libre, mientras que las colas resultantes del beneficio son propiedad de la Nación; estas colas, que para un lego en minería pasan por simples arenas residuales, concentran la mayor parte del mineral que se extrae en el proceso de beneficio y por ello hoy son reclamadas por los particulares dueños de los molinos a cambio de permitir a los pequeños mineros moler la "guacha" que extraen del socavón (González Colonia, 2012: III, 22).

Tiempo después, bajo el régimen del general Gustavo Rojas Pinilla se expidió el Decreto Extraordinario 2223 de 1954, con el propósito de regular la contratación de minas en Marmato ${ }^{19}$. Cuando se compara el contenido de la Ley 66 de 1946 y del Decreto 2223 de 1954 en apariencia son bastante similares. Pero hay una diferencia importante y es que este último abre expresamente la posibilidad de que también la zona alta A se contrate con un solo particular, preferiblemente con quien tenga a su cargo la explotación de la zona B, mientras que la Ley 66 no establecía dicha posibilidad. Es decir, el Decreto 2223 allanó de nuevo el camino para que una sola empresa monopolizara la explotación del recurso aurífero en Marmato; de hecho, buena parte de sus disposiciones se ocupan de regular las condiciones bajo las cuales se llevaría a cabo la contratación integral de ambas zonas.

Por eso llama la atención que en la memoria colectiva de muchos marmateños la división del cerro entre zona alta y baja esté asociada a la expedición del Decreto 2223, que en rigor lo que hacía era establecer la posibilidad legal de que el régimen de reparto del cerro volviera a desmontarse para entregar su explotación a una sola empresa, y en cambio se haya olvidado la referencia a

18 El Decreto reglamentario 1323 de 1947 se ocupa de establecer las condiciones para llevar a cabo dicha contratación.

19 Diario Oficial n. 28542 del 4 de agosto de 1954, pp. 322-323. 
las leyes 72 de 1939 y 66 de 1946, que fueron las que establecieron las condiciones para la convivencia de la pequeña y de la mediana minería en Marmato.

Si bien el Decreto 2223 no derogaba sino que suspendía temporalmente la vigencia de las citadas leyes 72 de 1939 y 66 de 1946, al finalizar el régimen de Rojas Pinilla los decretos expedidos durante su gobierno fueron convertidos en legislación permanente a través de la Ley 2 de 1958 y luego de la Ley 141 de 1961. Aunque estas normas abrieron la puerta para echar atrás el reparto del cerro entre pequeños y medianos mineros y en su lugar volver a un régimen de monopolio, lo cierto es que esta posibilidad no se concretó. Y el que no ocurriera tuvo que ver con varios factores: por un lado, dicho sistema contribuyó a resolver de una manera relativamente exitosa el problema social desencadenado por la dependencia de una sola empresa encargada de la producción. Pero igualmente, esta solución pudo persistir hasta finales del siglo XX debido a la conjunción de circunstancias económicas y políticas que favorecieron la consolidación de este modelo de distribución del territorio y del recurso aurífero: (i) durante varias décadas el precio del oro se mantuvo en niveles bajos, lo que desestimuló el interés de los grandes inversores por hacerse a la explotación de todo el cerro ${ }^{20}$; (ii) la minería dejó de ser un renglón de capital importancia para la economía nacional, al ser desplazada por la industria manufacturera, la agricultura y la ganadería, prueba de lo cual es que entre 1950 y 1990 la participación de la minería (incluyendo el petróleo) en el PIB se mantuvo por debajo del 5\% (Poveda Ramos, 2005); (iii) entre las décadas de 1940 y 1980 se mantuvo un modelo de intervención estatal en la economía y, específicamente, en la explotación de los recursos no renovables, que favoreció un relativo control sobre las condiciones en que se ejercitaba la pequeña minería, a la vez que permitió al Estado cumplir de manera más directa su función de distribuir entre todos los agentes sociales la posibilidad de acceder al recurso aurífero.

En definitiva, como señalan Mary Luz Sandoval y Melina Lasso, “con los decretos que disponen la zonificación de la explotación, los pequeños mineros de Marmato son reconocidos por el Estado como agentes activos de la economía minera", pues al garantizar su derecho a explotar la parte alta del Cerro, "les garantiza una participación en la distribución del capital generado por el oro" (Sandoval y Lasso, 2012: 179). A continuación veremos cómo

20 Entre 1934 y 1971 el precio del oro fue de 35 dólares la onza troy. Tras la liberación del precio en 1971 experimentó una importante alza que alcanzó su máximo en 1980, cuando llegó a los 682 dólares la onza; luego el precio descendió y se mantuvo con algunas variaciones hasta 2001, cuando registró un precio mínimo de 254 dólares la onza, a partir del cual inició de nuevo una tendencia alcista que alcanzó su pico máximo en septiembre de 2011, cuando llegó un precio de 1.825 dólares la onza (Poveda Ramos, 2005; World Gold Council, 2012). 
esta distribución territorial se mantiene, aunque no exenta de dificultades, en la legislación minera expedida en las décadas posteriores, configurando la manera en que los marmateños conciben y construyen su territorio y su identidad como mineros.

Figura 1. Distribución territorial efectuada por la Ley 66 de 1946 y mantenida por el Decreto 2223 de 1954

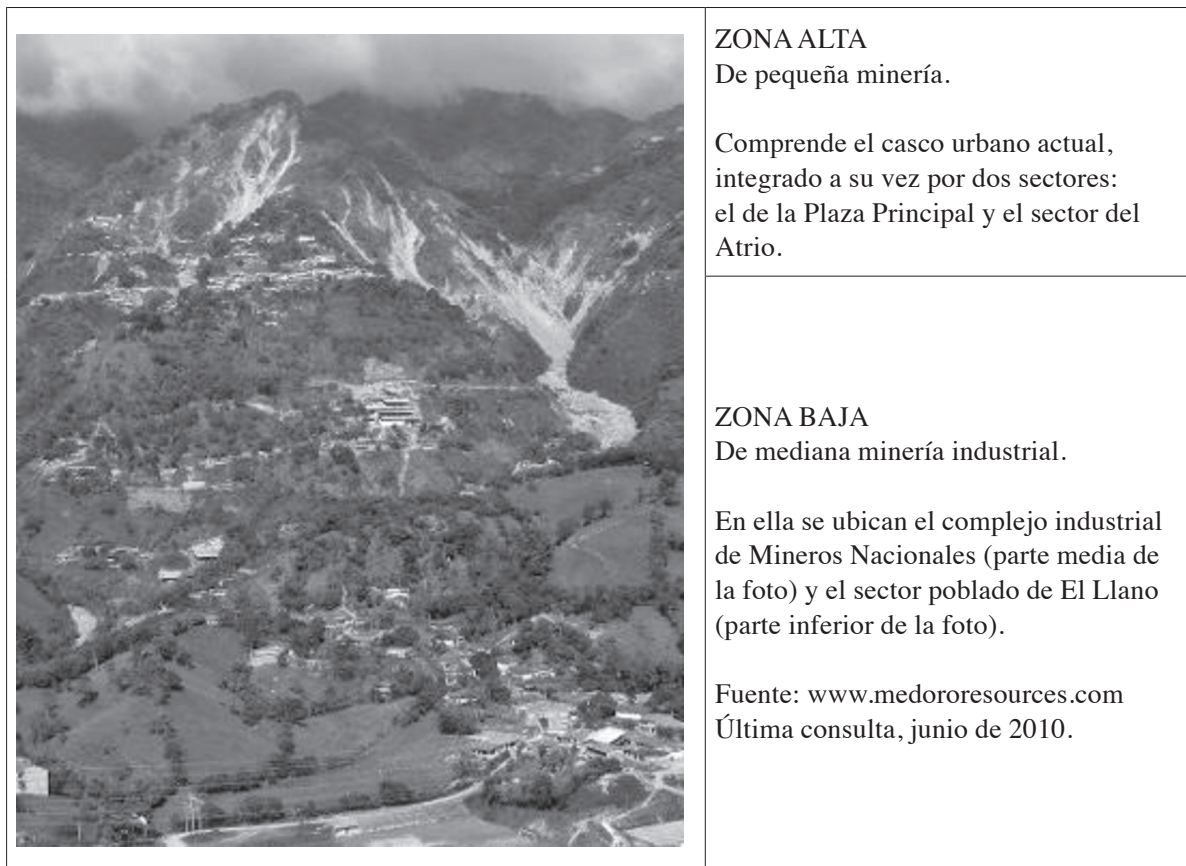

II. PERVIVENCIA DEL RÉGIMEN ESPECIAL PARA MARMATO EN LA LEGISLACIÓN POSTERIOR Y SU INFLUENCIA EN LA CONSTRUCCIÓN DE TERRITORIALIDAD E IDENTIDAD DE SUS HABITANTES

Tras la expedición de la Ley 20 de 1969, reglamentada por el Decreto 1275 de 1970, se eliminó el antiguo sistema de adjudicación ${ }^{21}$ para establecer que, en adelante, los derechos sobre las minas solo podrán concederse a través

21 La adjudicación minera es definida como "un acto administrativo por el cual el Estado se desprendía del dominio de una mina adjudicable para transferirlo a un particular bajo condiciones", principalmente, el pago del llamado impuesto de "estaca" y la obligación de explotar las minas. Algunas minas adjudicadas fueron "redimidas o amparadas a perpetuidad", a través del pago anticipado del impuesto correspondiente a 20 años (Aramburo Restrepo, 1980, 61-62). 
de las figuras de concesión, aporte y permiso ${ }^{22}$. Sin embargo, dicha legislación reconocía el derecho de los particulares sobre las minas que habían sido adquiridas por adjudicación y redención a perpetuidad, entre otros medios, siempre que las minas sean explotadas y su explotación no se suspenda por más de un año; es en virtud de esta norma que se establece el reconocimiento de propiedad privada -RPP 357- sobre la zona minera de Echandía (Arias y Adarve, 2004: 69). En cuanto a las demás minas de Marmato, comprendidas dentro de la categoría de minas de reserva especial del Estado, se dispuso que quedarían sometidas al régimen especial vigente, al término del cual "su explotación se hará directamente por la Nación o por el sistema de concesión o aporte a favor de empresas comerciales de la Nación o a sociedades de economía mixta que tengan participación oficial mínima del $51 \%$ del respectivo capital" (art. 8. ${ }^{\circ}$ de la Ley 20 de 1969 y art. 31 del Decreto 1275 de 1970).

Fue así como en la década de 1970 el control de las minas de Marmato siguió a cargo del Ministerio de Minas, a través del Administrador de las Minas Nacionales ${ }^{23}$, quien se ocupaba de ordenar la explotación en la zona alta a través de la celebración de contratos y el otorgamiento de permisos a los pequeños mineros, como también de administrar directamente los molinos El Colombiano, Cien Pesos y Santa Cruz donde aquellos beneficiaban el mineral. Asimismo, tuvo a su cargo la administración directa de la zona baja hasta tanto surgiera una empresa en condiciones de contratar su explotación.

En los archivos de las minas de Marmato que hoy reposan en la Delegación Minera de Caldas se encuentran documentos de la época en que el Administrador de las Minas Nacionales de Marmato mantuvo el control de la zona alta $\mathrm{A}$, los cuales testimonian las escasas formalidades que acompañaban la cesión de derechos de explotación sobre las minas, el respaldo a los créditos contraídos por los mineros para la compra de insumos y, en general, las relaciones entre los mineros y los funcionarios de la Administración de

22 La concesión minera constituye un contrato o un acto administrativo mediante el cual el Estado otorga a un particular o a una entidad pública o mixta un derecho de explotación temporal sobre una mina de la Nación, en las condiciones establecidas por la ley.

El aporte es "el acto administrativo en virtud del cual el Estado confiere un derecho de explotación de un yacimiento de minerales básicos para la economía nacional a un establecimiento público, una empresa industrial o comercial del Estado o una empresa mixta con predominio de capital oficial. Es el medio a través del cual participa el Estado en la industria minera".

El permiso de explotación es una concesión efectuada a través de un acto administrativo unilateral. Se efectúa sobre un área más reducida, tiene una duración menor y otorga ciertas facilidades como la exoneración de regalías y de reversión, razón por la cual puede considerarse como una "concesión menor" orientada a promover la pequeña minería (Aramburo Restrepo, 1980: 62-66).

23 Que continuaba con la figura del Director de Minas, establecida desde la Ley 72 de 1939 y mantenida en los decretos 2223 y 3068 de 1954. 
Minas $^{24}$. Asimismo, dejan ver un patrón de ordenación de los trabajos mineros basado en acuerdos verbales y en un sistema de distribución vertical (por cotas) de los derechos de explotación en la zona alta ${ }^{25}$, al igual que el recurso a otras reglas de origen consuetudinario para dirimir conflictos cotidianos, como los surgidos por la interferencia de trabajos mineros o la asignación de turnos para la molienda del material ${ }^{26}$.

24 Así, por ejemplo, en comunicación del 13 de julio de 1973, el señor GonZALO GARCíA da a conocer al Administrador de las Minas Nacionales de Marmato "que a partir de la fecha he autorizado al señor OSCAR GARCÍA RESTREPO para que trabaje dentro de la mina Santa Inés y de la cual soy arrendatario, un tambor que previamente le he asignado. El señor GARCÍA RESTREPO está plenamente autorizado por mi para que pida en el Almacén de las Minas los materiales que necesite para adelantar sus trabajos, convirtiéndome de antemano en fiador o responsable de un posible incumplimiento por parte de él".

Tiempo después, el 12 de junio de 1976, el Administrador de las Minas expide un certificado dirigido a respaldar un préstamo que el señor OSCAR GARCíA tramitaba ante la Caja de Crédito Agrario, en el que hace constar que este último venía trabajando desde hace más de un año un sector de la mina Santa Inés. Aclara, no obstante, que "no se le expide constancia como arrendatario, ya que solamente trabaja en un sector de la mencionada mina con autorización del arrendatario de ésta, señor GONZALO GARCía RESTREPO, su hermano": Delegación Minera de Caldas, exp. CHG-081, fols. 8 y 9.

25 A propósito de una disputa de linderos entre los arrendatarios de las minas La Floresta y Santa Inés se encuentra un documento del 25 de junio de 1943 en el que, además de la distribución vertical de los derechos de explotación, se evidencia que algunos contratos de arrendamiento ni siquiera constaban por escrito. En esta comunicación el entonces Director de Minas de Marmato señala que "aun cuando referente a la mina de Santa Inés no existe otra documentación que un memorial de fecha abril 9/1940 en el cual se pide la expedición de una licencia dando como lindero vertical superior el nivel de la mina 'La Floresta', este lindero está tácitamente en vigencia. La distancia vertical entre las bocaminas de Santa Inés y de la Floresta es de 57.05 metros": Delegación Minera de Caldas, exp. CHG-081, fol. 6.

26 Para la época solo existían tres molinos (Santa Cruz, Cien Pesos y El Colombiano) para beneficiar el mineral extraído en la zona alta, lo que obligaba a cada minero a esperar durante varios meses la llegada de su turno. Esto originaba frecuentes disputas como la que se documenta en este oficio del 12 de enero de 1977, dirigido por el Administrador de las Minas al señor GonZALO GARcía: "En el día de hoy se presentó a las oficinas de la Administración de Minas el señor Bernardo Rincón reclamando para él y su socio [...] el turno para la molienda de sus minerales, en vista de que se están incumpliendo por parte suya las disposiciones tomadas por esta oficina.

"En el día de ayer esta oficina ofició a Ud. advirtiéndole que solamente se le daba turno para moler los minerales que le compró al señor LuIS CARLOS RODAS, toda vez que era a este señor a quien le correspondía el turno. La Administración accedió a que Ud. beneficiara estos minerales contraviniendo su reglamentación, pues el señor RODAS al vender sus minerales perdía el turno que le pudiera corresponder. Pero Ud. ha aprovechado la oportunidad para embarcar también los minerales de su mina, lo que le está completamente prohibido por no corresponderle el turno": Delegación Minera de Caldas, exp. CHG-081, fol. 14. 


\section{1980-2000: "Del socavón al expediente". De la administración directa a una ordenación cada vez más remota, mediata y uniforme de las minas de Marmato}

El Decreto 2064 de 1980 ratificó el régimen de reserva especial al que estaban sometidas, entre otras, las minas de propiedad nacional conocidas con el nombre genérico de minas de "Marmato, Supía y distritos vecinos", pero dispuso que en adelante su administración quedaría en manos de la Empresa Colombiana de Minas - ECOMINAS, a quien le fueron entregadas a título de aporte ${ }^{27}$. Con fundamento en ello el Ministerio de Minas y Energía otorgó a ECOMINAS el aporte 1017, con una extensión de 7.200 hectáreas, dentro del que se incluían las minas nacionales de Marmato; también suscribió un contrato de administración delegada, que facultaba a dicha entidad para ordenar la explotación de las minas localizadas dentro del área destinada a los pequeños mineros (Arias y Adarve, 2004: 86-88, 95-107). Durante este período las relaciones contractuales con los mineros de la zona alta mantuvieron el escaso nivel de formalización que hasta entonces las había caracterizado. Solo hacia el final de la década, tras la expedición del Código de Minas de 1988, se advierte una tendencia hacia la formalización de estas relaciones, entre otras razones debido a la entrada en vigencia del catastro minero, que obligaba a registrar en el término de un año los contratos y demás títulos mineros vigentes so pena de declarar su extinción ipso iure (art. 296 del Decreto 2655 de 1988). En este contexto, ECOMINAS impulsó la firma de "contratos para la exploración y explotación de metales preciosos de pequeña minería en las minas nacionales de Marmato zona alta", incluidos bajo la modalidad de "contratos en virtud de aporte", cuya duración coincidía con la vida útil del yacimiento; sin embargo, de acuerdo con las cifras suministradas por la Jefe de la Delegación Minera de Caldas, apenas 5 o 6 de las explotaciones que de tiempo atrás se venían realizando pasaron a ser reguladas bajo esta figura $^{28}$. También para esta época, ECOMINAS entregó la explotación de la zona baja B a la sociedad "Domínguez Saieh Cía. Ltda.", a través de un contrato de operación para la exploración y explotación suscrito el 4 de abril de 1989,

27 El Código de Minas expedido mediante Decreto 2655 de 1988 ratificó la condición de reserva especial de las minas de Marmato y su tratamiento bajo el régimen de aporte (art. 320). Sin embargo, dejó abierta la posibilidad de que el Ministerio las modifique o elimine, para someterlas al régimen común (art. 322).

28 Entrevista a LuZ Adriana Arias, Jefe de la Delegación Minera de Caldas, 3 de julio de 2012. Uno de los contratos suscritos bajo esta modalidad es el 4467 , correspondiente a la mina Patacón. Delegación Minera de Caldas, exp. 4467, fol. 5-12. Su registro en el catastro minero puede consultarse en: http://www.cmc.gov.co:8080/CmcFrontEnd/consulta/listaResultado.cmc 
por un término de 30 años, y que poco tiempo después sería asumido por Mineros Nacionales S.A. ${ }^{29}$.

Por otra parte, aunque el Código de 1988 mantiene la distinción entre pequeña, mediana y gran minería (art. 15), estableciendo obligaciones diferenciadas para cada uno de estos sectores, algunas de sus normas comienzan a allanar el camino para el desplazamiento de la pequeña minería en zonas donde se pretenda desarrollar proyectos de gran minería ${ }^{30}$. Tendencia que continúa perfilándose en las décadas siguientes cuando, a tono con el viraje hacia el neoliberalismo propiciado por la reforma constitucional de $1991 \mathrm{y}$ los acuerdos suscritos a finales de esta década con el Fondo Monetario Internacional, tuvo lugar una importante reestructuración de la institucionalidad minera que marcó el fin del modelo de Estado empresario, preparando las condiciones para su total retiro de la gestión directa de los recursos mineros; retiro que coincidirá con la llegada de empresas transnacionales que pasan a ocupar un lugar predominante en el campo de la minería del oro (Lasso Lozano, 2011: 63-68; Fierro Morales, 2012: 35-36). Es así como la Ley 2 de 1990 dispuso la liquidación de ECOMINAS para crear en su reemplazo la Sociedad Minerales de Colombia - Mineralco S.A. Poco tiempo después, mediante Decreto 1679 de 1997, esta última se fusionó con ECOCARBÓN para dar origen al MINERCOL Ltda., entidad que, entre sus muchas funciones, tuvo a su cargo la administración de las minas de Marmato hasta su liquidación definitiva en 2004. Tras la liquidación de MINERCOL, y bajo el marco del Código de Minas expedido en 2001, el Estado dejó en manos del capital privado todas las faenas que demanda la explotación y beneficio de los recursos mineros, para concentrarse en el otorgamiento de títulos y fiscalización de la actividad minera, lo que en el caso de Marmato se ha realizado a través de la Delegación Minera de Caldas y de INGEOMINAS ${ }^{31}$.

29 Este contrato figura en la Delegación Minera de Caldas, exp. 014-89M. Su registro en el catastro minero puede consultarse en: http://www.cmc.gov.co:8080/CmcFrontEnd/consulta/ listaResultado.cmc

30 Ello se advierte de manera clara en el artículo 90, donde se dispone que "en la contratación de zonas para proyectos de pequeña y mediana minería o con organizaciones cooperativas o precooperativas, que realicen los organismos descentralizados dentro del área de sus aportes, los términos, condiciones y modalidades, las señalará o autorizará la junta o consejo directivo, por vía general o en cada caso. En estos contratos se incluirán cláusulas que prevean la no interferencia de estos proyectos a los de gran minería que eventualmente abarquen la misma zona o su obligatoria integración a éstos sin desmejorar las condiciones económicas de los interesados que se hayan de integrar".

31 Entidades que, tras la última reestructuración de la institucionalidad minera, han pasado a depender de la recién creada Agencia Nacional de Minería. 
No se trató solo de un cambio de siglas, sino de un adelgazamiento progresivo de la institucionalidad estatal encargada de ordenar la administración del recurso minero y, en consecuencia, de un control cada vez más remoto y más débil sobre las minas de Marmato. Ello se tradujo en un aumento de los conflictos entre los mineros de la zona ante el progresivo retiro de la autoridad encargada de velar por el respeto a las normas que establecían la distribución de los derechos de explotación en el cerro y los criterios para su manejo técnico y ambiental. Al respecto resulta significativo que los marmateños identifiquen la fecha en que las instituciones estatales abandonaron la administración de la zona alta no con el año 2004, cuando se liquida MINERCOL, sino con el comienzo de los años 90, cuando se liquida ECOMINAS y el Estado deja de operar directamente las plantas de beneficio de El Colombiano, Santa Cruz y Cien Pesos. A partir de ese momento, varios de los entrevistados coinciden en afirmar que "el Estado se desentendió de Marmato" y comenzaron a agravarse problemas como los ocasionados por la inadecuada disposición de los residuos derivados de la explotación ${ }^{32}$.

A estas dificultades se sumó el desorden que introdujo la propia autoridad minera. Según explican Jorge Humberto Arias y Gerardo Adarve, tanto ECOMINAS como las empresas que le sucedieron propiciaron una confusión de regímenes jurídicos debido a que las decisiones relativas a la contratación y permisos de explotación sobre las áreas del aporte en ocasiones se regían por las normas generales que regulaban la administración de los aportes, en lugar de por las normas vigentes que definían el régimen de contratación y administración especial para Marmato (Arias y Adarve, 2004: 121).

Entre las circunstancias que han contribuido a generar tal río revuelto de normas, decisiones administrativas y situaciones de hecho que tornan singularmente complejo el intento de descifrar la situación jurídica de las minas de Marmato, hemos identificado las siguientes: (i) deslocalización de la autoridad minera; (ii) desplazamiento del régimen especial por la aplicación de la normatividad general para emprender la formalización de los mineros de la zona alta; (iii) no reconocimiento en el registro minero del sistema de titulación por cotas; (iv) consolidación de un modelo de desarrollo minero que desplaza la pequeña minería en beneficio de la concentración de la propiedad minera y la explotación a gran escala. Veamos.

32 Incluso algunos, como don Eulises Lemus, consideran que la retirada del Estado tuvo lugar desde los años 80, cuando desaparece la figura del Administrador de Minas de Marmato y, en su lugar, se firma el contrato de administración delegada con ECOMINAS pues, de acuerdo con su percepción, "no se trataba de una entidad propiamente estatal como el Ministerio, sino de una empresa en la cual el Estado tenía una participación apenas indirecta": entrevista, 25 de junio de 2012. 
(i) El régimen especial que venía operando desde los años 40 había funcionado gracias a la existencia de una institucionalidad estatal -encarnada en la figura del Director y luego del Administrador de las Minas Nacionales de Marmato-que tenía una relación directa con los mineros y tomaba in situ, muchas veces en el mismo socavón, las decisiones relativas a la ordenación del territorio minero. En la medida en que tal institucionalidad es desmontada, tales decisiones pasan a depender de funcionarios que ejercen un control cada vez más remoto de la situación y que en muchos casos solo tienen un conocimiento del territorio mediado por los informes técnicos de los funcionarios que de manera esporádica eran comisionados para hacer visitas de inspección y seguimiento a las minas. Es significativo, por ejemplo, el paso de un sistema de contratación predominantemente verbal y que admitía fijar por mutuo acuerdo algunas condiciones (p. ej., las relativas a la duración del contrato), como fue el surgido al amparo de legislación expedida entre los años 30 y 50, a minutas de contratos elaboradas por los abogados desde las oficinas centrales de ECOMINAS, MINERALCO y MINERCOL en Bogotá o en la Delegación Minera de Caldas, que son enviadas para su firma a los mineros de Marmato $^{33}$. De acuerdo al esquema de dominación legal que rige la actuación administrativa, este tránsito podría interpretarse como un paso hacia la gestión más racional de los recursos mineros ${ }^{34}$; sin embargo, al evaluar su pertinencia en un contexto social específico, como el que aquí se analiza, no necesariamente se traduce en una mejor ordenación del territorio y de las relaciones entre las personas que lo habitan, como tampoco en una mejor administración de los recursos del subsuelo.

(ii) Esta deslocalización de la autoridad minera favoreció la tendencia a la estandarización, dando prioridad a la aplicación de la normatividad general sobre las normas especiales que regulaban la contratación en Marmato, pese

33 En los expedientes de las Minas Nacionales de Marmato que alcanzamos a revisar en la fase de recolección de información para esta investigación no se encontraron contratos suscritos durante el tiempo en que operaron la Dirección y la Administración de Minas de Marmato. Aunque no se logró una revisión exhaustiva de todos los expedientes, la dificultad para hallar soportes escritos de los contratos celebrados en esta época corrobora la afirmación de varios entrevistados, entre ellos el abogado DIEGo ARMANDo RUIZ, quien manifestó su desconcierto al constatar cómo "A partir del 53 los contratos el Ministerio comenzó haciéndolos verbales, no eran contratos escritos; supuestamente contratos verbales, que uno no entiende cómo el Estado hace contratos verbales": entrevista, 10 de julio de 2012.

34 Como ya lo señalara MAX WEBER, en la dominación legal "rige el principio de atenerse al expediente, aun allí donde las declaraciones orales sean de hecho la regla o estén hasta prescritas; por lo menos se fijan por escrito los considerandos, propuestas y decisiones, así como las disposiciones y ordenanzas de toda clase. El expediente y la actividad continuada por el funcionario hacen que la oficina sea la médula de toda forma moderna en la actividad de las asociaciones" (WEBER, 1997: 175, resaltado original). 
a que estas últimas formalmente mantenían su vigencia. $\mathrm{Si}$, como señala el positivismo jurídico de orientación realista, la vigencia de las normas depende, en definitiva, de la creencia compartida en su obligatoriedad (Ross: 1997: 60 ), podría afirmarse que la creencia en la vigencia de las viejas normas que definieron el régimen especial para Marmato comenzó a erosionarse y a ser puesta en duda como resultado de las decisiones de la autoridad minera que hicieron a un lado su aplicación desde finales de los años 80 .

A lo anterior vino a sumarse el creciente interés de la autoridad minera en formalizar la situación de los mineros de la zona alta, utilizando para ello no el viejo régimen especial, que 40 años después posiblemente resultaba desconocido para los abogados capitalinos, sino la normatividad general prevista para la legalización de los mineros de hecho. Dado que los "contratos en virtud de aporte" suscritos con ECOMINAS no habían alcanzado a cumplir con tal cometido, para mediados de los años 90 MINERALCo requirió a todos los pequeños mineros de Marmato para someterse al programa de legalización de explotaciones de hecho establecido en el artículo 58 de la Ley 141 de 1994.

Analistas como Jorge Humberto Arias y Gerardo Adarve sugieren que dicha normatividad no era aplicable a los mineros de la zona alta A de Marmato, por cuanto estos no adelantaban una explotación sin título, sino al amparo del aporte 1017, con la autorización y bajo la supervisión del Administrador de Minas y luego de las empresas estatales que sucesivamente asumieron la administración de las Minas Nacionales de Marmato (ECOMINAS - MINERALCO), razón por la cual no eran propiamente "explotadores de hecho" 35 . Al emplear este procedimiento de legalización para "poner orden en casa" y proceder a formalizar la actividad que venían realizando los mineros en la zona alta A, la autoridad minera hizo tabula rasa del pasado, dejando de lado la cantidad de pequeños contratos que presumiblemente se apiñaban en desorden en sus oficinas o que ni siquiera reposaban por escrito, pero que hasta entonces habían regido la relación entre el Estado y los pequeños mineros tradicionales de Marmato. De este modo, concluyen Arias y Adarve, al negar el derecho de los pequeños mineros de Marmato, derivado de la vieja legislación de los años 30 a 50 a la que ya hemos hecho alusión, para en su lugar darles el tratamiento (indebido según la propia normatividad vigente) de mineros de hecho, se conculcaron los derechos históricos de muchos pequeños mineros de la zona alta de Marmato (Arias y Adarve, 2004: 131-136).

35 De acuerdo con la definición establecida en el artículo 1. . del Decreto 2636 de 1994 (que reglamentaba el artículo 58 de la Ley 141 de 1994), la expresión "explotadores mineros de hecho" solo resulta aplicable a las personas que llevaran a cabo la explotación de yacimientos mineros sin contar con título minero vigente. 
De acuerdo con las cifras suministradas por la Jefe de la Delegación Minera de Caldas, a través del programa de legalización establecido en la Ley 141 de 1994 se suscribieron alrededor de 122 contratos de pequeña minería; cerca del $90 \%$ de los títulos existentes en la zona alta surgieron de este proce$\mathrm{so}^{36}$. Estos resultados, que contrastan con las cifras muchísimo más modestas que han arrojado otros procesos de legalización ${ }^{37}$, tal vez puedan explicarse porque su realización coincidió con la llegada a Marmato, hacia 1995, de la empresa Corona Goldfiels, interesada en adquirir títulos en la zona alta. Según lo explican dos abogados que prestan sus servicios a los mineros de Marmato, "a partir de la expedición de la Ley 141 comienza el proceso de legalización porque hay una multinacional que llega a Marmato que se llama la Corona Goldfields y ella necesita para poder adquirir los derechos de los mineros que eso tenga títulos. Ellos son los que impulsan la legalización de los mineros a través de esa ley que sacó el Congreso" 38 .

36 Entrevista a LuZ Adriana Arias, Jefe de la Delegación Minera de Caldas, 3 de julio de 2012 .

37 Según datos suministrados por la Jefe de la Delegación Minera de Caldas, tan solo se alcanzaron a suscribir 5 o 6 contratos en virtud del aporte 1017 en la zona alta. En cuanto al programa de legalización establecido en la Ley 685 de 2001, aunque se recibieron cerca de 300 solicitudes, únicamente 14 lograron superar los requisitos establecidos, pero la firma de los contratos se encuentra a la espera de resolver los problemas para su inscripción en el registro minero. Fuente: Reunión con la comunidad minera de Marmato y representantes del Ministerio de Minas, Marmato, 13 de abril de 2012. Entrevista realizada el 3 de julio de 2012.

38 Entrevista a Lina María CáRdenas y Diego Armando Ruiz, 10 de julio de 2012. El interés de la Corona Goldfields por sacar adelante este proceso de legalización se corrobora al leer el expediente en el que se surtió el correspondiente trámite ambiental ante Corpocaldas, donde consta la asistencia de representantes de esta compañía a una reunión celebrada el 4 de octubre de 1997 entre MINERALCO e integrantes de las asociaciones de mineros del municipio, con el fin de discutir la minuta de los contratos de legalización (f. 224). También reposa un informe de visita efectuada por Corpocaldas el 11 de mayo de 1998, en cuyo encabezado se afirma que el interesado en el trámite es la Corona Goldfields (en lugar de MINERALCO, en su calidad de titular del aporte 1017 y quien sufragó con recursos públicos los costos del programa de legalización). Sin embargo, en un intento de poner orden en tal confusión de roles, en las conclusiones de este informe se aclara "que MINERALCO es el responsable de la ejecución de las obras propuestas, por lo que el sentido de CORONA GOLFIELDS es simplemente de colaboración"; en cualquier caso, se envía copia del informe a la mencionada compañía (f. 256-258). Finalmente, el interés de la mencionada compañía en acompañar el proceso de legalización de los pequeños mineros de la zona alta queda claro en el oficio del 15 de diciembre de 1997, en donde el gerente de MINERALCO solicita a Corpocaldas atenuar las obligaciones ambientales impuestas a los mineros que se acogieron al programa de legalización e imponerles un Plan de Manejo Ambiental a corto plazo, "ya que se contempla la posibilidad de que a través de dos empresas Mineros de Antioquia S.A. y Corona Goldfields S.A. se desarrolle un proyecto de Gran Minería a gran escala, lo que cambiaría radicalmente el panorama minero de Marmato" (f. 233-234). Dos años después, el interés en llevar a cabo este proyecto sigue en firme, según se expresa en oficio del 3 de noviembre de 1999, mediante el cual MINERCOL remite a Corpocaldas un nuevo Plan de Manejo Ambiental. 
(iii) Pero según la legislación minera colombiana, un título solamente surte efectos cuando es inscrito en el registro minero. Y es aquí donde la inadecuación de los instrumentos diseñados para estandarizar la gestión de la titulación minera alcanza sus máximos niveles de irracionalidad. Siguiendo la tradición de ordenación escalonada del territorio y de distribución vertical de los trabajos mineros, sobre la cual se basa la distribución del cerro en zona alta y baja establecida por la legislación de los años 40 y 50, la asignación de derechos de explotación en la zona alta ha operado de acuerdo a un sistema de cotas. Al preguntarle a don Eulises Lemus, marmateño con amplio conocimiento de temas mineros, por el origen de este peculiar sistema de titulación, explica que no existe ninguna norma que lo consagre, al menos él no la conoce, pero que fue la manera en que por muchos años el propio Estado distribuyó los derechos de explotación sobre la parte alta del cerro: "usted puede llegar hasta donde comienza la mina del otro, para que no lo desfonde". Y en un terreno pendiente como el de Marmato, que además concentra gran cantidad de trabajos mineros, especialmente en la zona alta, la mina del otro no se encuentra solo al lado, sino que suele estar por encima o por debajo.

Figura 2. Vista de las bocaminas en el sector de Cien Pesos

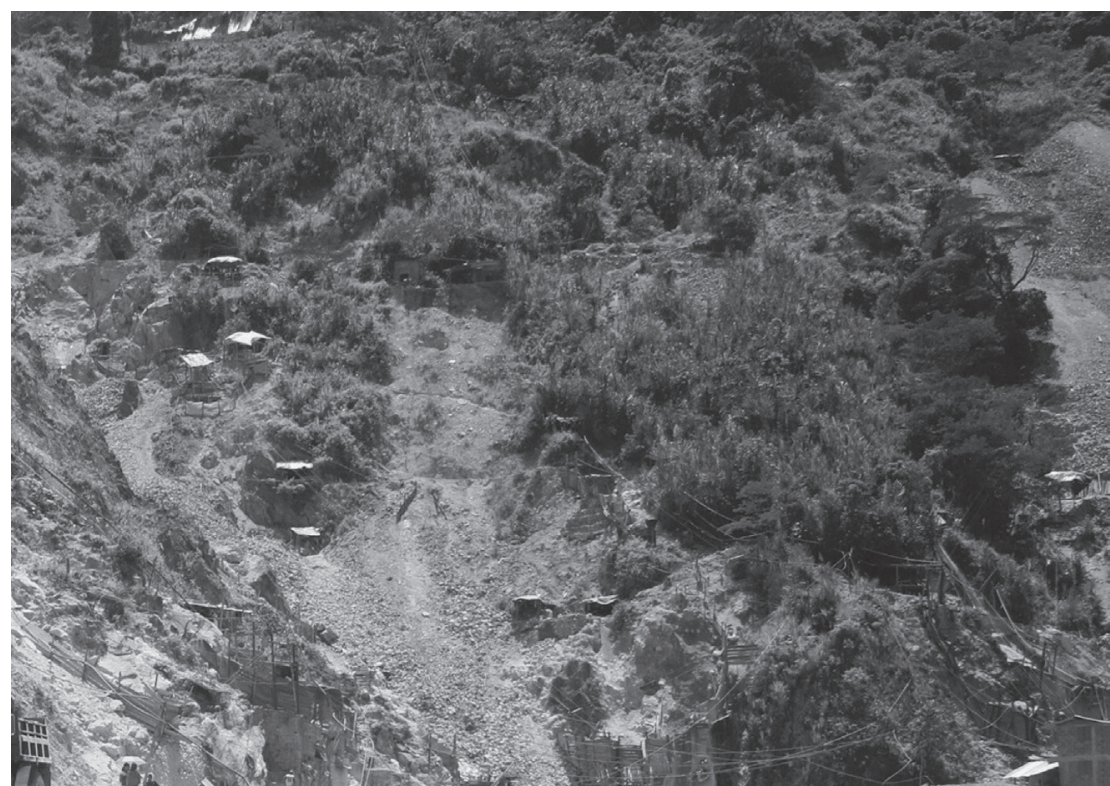

Entre las obligaciones a las que se compromete MINERCOL figura la "negociación de un proyecto de gran minería, el cual se desarrollará en la zona alta de Marmato, donde se halla una gran concentración de pequeños mineros" (f. 322). Corpocaldas, expediente de legalización de pequeña minería en la parte alta de Marmato, rad. n. ${ }^{\circ} 298$. 
Así las cosas, cuando los contratos de pequeña minería suscritos en virtud de la Ley 141 de 1994, en su mayoría elaborados en el año 1998, fueron llevados al registro se encontró que el sistema no permitía inscribirlos porque presentaban superposición con otros títulos que habían sido previamente inscritos, en especial con el contrato de mediana minería que amparaba a Mineros Nacionales para explotar la zona baja de Marmato $(014-89 \mathrm{~m})^{39}$. La dificultad se origina en que el catastro minero funciona de acuerdo a un sistema de coordenadas planas que no permite la titulación por cotas, esto es, la inscripción de títulos otorgados sobre una misma área pero a diferente altura.

Con el ánimo de resolver este problema, y de paso allanar el camino al proyecto de gran minería que desde entonces comenzaba a gestarse, en junio de 1999 MINERCOL propuso a Mineros Nacionales la integración de las zonas alta y baja "para desarrollar un proyecto de gran minería a cielo abierto". Al no recibir respuesta de esta última empresa, y ante la inminente llegada a su fin del sistema de aportes (que desapareció con la expedición de la Ley 685 de 2001), MINERCOL emprendió un programa de unificación de explotaciones mineras en la zona alta A, basado en la división de esta zona en tres niveles, cada uno de los cuales estaría regido por un contrato de mediana minería -"técnica y ambientalmente viable"- suscrito de manera conjunta por todos los titulares mineros del respectivo nivel ${ }^{40}$. Lo llamativo de esta propuesta es que, pese a que formalmente pretende ser una solución al problema que plantea el registro de contratos por cotas, no hace sino confirmar lo arraigado que está dicho sistema de asignación de derecho de explotación en el cerro, no solo entre los marmateños sino entre los propios funcionarios encargados de ordenar el ejercicio de la minería, pues precisamente se basa en una reordenación de la zona alta sobre la base de un sistema de cotas, así:

39 Así lo explica Corpocaldas en oficio del 10 de mayo de 2004 mediante el cual da respuesta a un requerimiento formulado por la Procuraduría. El oficio señala que "dentro de ese proceso de legalización, Minercol suscribió 108 contratos en 1998, que no han sido inscritos en registro minero por la superposición existente entre ellos y el contrato 014-89M de Mineros Nacionales y la inactividad de los mineros para iniciar trámites correspondientes": Corpocaldas, exp. 616, fol. 290 .

40 Según lo afirma María InÉs CASTRo de ArIZA, la entonces Presidente de MINERCOL, en oficio 1081-07850 del 27 de septiembre de 2000. Documento suministrado por LiNA MARÍA CÁrdenas y Diego Armando Ruiz. 
Tabla 1. Propuesta de integración en tres niveles de la zona alta impulsada por MINERCOL

\begin{tabular}{|l|l|l|}
\hline Niveles zona alta & \multicolumn{1}{|c|}{ Cota inferior } & \multicolumn{1}{c|}{ Cota superior } \\
\hline Nivel uno & $\begin{array}{l}\text { Limita con la cota superior del contrato } \\
\text { 014/89M (Mineros Nacionales) }\end{array}$ & 1.363 m.s.n.m. \\
\hline Nivel dos & 1.363 m.s.n.m & 1.500 m.s.n.m. \\
\hline Nivel tres & 1.500 m.s.n.m. & $\begin{array}{l}1700 \text { m.s.n.m. (altura máxima del } \\
\text { cerro El Burro) }\end{array}$ \\
\hline
\end{tabular}

En ejecución de este programa tan solo alcanzó a firmarse un contrato, el CHG-081, correspondiente al nivel uno, el cual, finalmente, logró ser inscrito en el registro minero, al igual que los pequeños contratos suscritos en los niveles dos y tres de la parte alta del cerro dentro del programa de legalización de la Ley 141 de 1994 y los pocos contratos en virtud de aporte que habían sido celebrados tras la expedición del Decreto 2655 de $1988^{[41]}$. El que para entonces se haya logrado sortear la dificultad que planteaba el registro de estos contratos, pese a que todos definían sus áreas a partir de un sistema de cotas, es una cuestión que tal vez se comprende mejor prescindiendo de las consideraciones técnicas y jurídicas del sistema de registro minero, para en cambio indagar por la disposición de los actores en el campo en el momento específico en que se impulsó este programa de legalización: de un lado, una gran empresa interesada en comprar a los pequeños mineros sus derechos de explotación (para lo cual requería títulos debidamente inscritos); de otro, unos mineros locales interesados en no quedar en condición de ilegales y/o cotizar al alza sus derechos ante la expectativa de una eventual negociación; y en medio de ambos, una autoridad minera en disposición de no entorpecer dicha negociación, la cual, entre otras ventajas, le permitiría reducir la complejidad que supone inscribir más de un centenar de contratos y lidiar con cientos de pequeños titulares mineros para, en su lugar, tratar de concentrar de nuevo la propiedad minera en la perspectiva de llegar a entregar de nuevo la explotación de todo el cerro a un solo (gran) titular ${ }^{42}$.

41 La inscripción en el registro del contrato CHG-081 tuvo lugar el 4 de febrero de 2002. Los demás contratos de pequeña minería suscritos dentro del programa de legalización de la Ley 141 de 1994 se firmaron en 1998 y, finalmente, lograron ser registrados en 2004. Por su parte, uno de los pocos contratos en virtud de aporte firmados en la zona alta, correspondiente a la mina Patacón (4467), se firmó el 4 de junio de 1990 y tan solo fue inscrito el 18 de marzo de 2005 .

42 Algunas piezas de correspondencia de la época documentan las dudas que originaba la posibilidad de registrar contratos por cotas y la disposición de la autoridad minera de ese entonces para encontrar una salida jurídica al problema. En un oficio del 19 de julio de 1996, firmado por 
Para efectos de nuestro análisis interesa destacar que la estrategia de formalización impulsada en la zona alta por la autoridad minera, y que condujo a la firma del contrato CHG-081, no logró su propósito declarado de mejorar la viabilidad técnica y ambiental de las explotaciones ${ }^{43}$, pero en cambio sí constituyó, al menos formalmente, el primer paso en firme para acabar con el régimen de pequeña minería imperante en la zona alta del cerro. Sin embargo, ello no fue percibido así por los pobladores, pues la integración del nivel inferior de la zona alta bajo un contrato de mediana minería no alteró la forma como los mineros seguían trabajando y disponiendo de sus derechos sobre las minas. Incluso en muchas de las anotaciones del registro minero donde consta la cesión de derechos de alguno de los titulares del contrato CHG-081 se indica de manera expresa la mina que estaba siendo objeto de transacción. Así, por entre las rendijas de las formas registrales de un contrato de mediana minería, expedido con la pretensión de integrar y disciplinar lo que (desde la racionalidad cartesiana de las recién creadas instituciones que pretendían ejercer un control a distancia del distrito minero de Marmato) era percibido como un caos de pequeños socavones sin orden ni concierto, se colaba una

JAVIER Ortiz MuÑoz, Jefe de la División Legal de Minas del Ministerio de Minas y Energía, se resuelve una consulta formulada por MINERALCO S.A. acerca de la inscripción en el registro minero de los contratos suscritos con ocasión del programa de legalización minera dentro del aporte 1017, afirmando que "no existe ningún impedimento de orden jurídico para proceder a inscribir tales explotaciones en el registro minero", debido a que el contrato de mediana minería suscrito en la zona baja excluye del área contratada la zona alta. Diez años más tarde, la autoridad minera sostenía la misma opinión, como se constata en oficio del 23 de agosto de 2006 , firmado por Hugo ALEJANDRo SÁNCHEZ HERNÁNDEZ, Subdirector de Contratación y Titulación Minera de INGEOMINAS, donde tras examinar las normas relativas al registro y a la superposición de áreas concluye que, "tanto en la normatividad actual, como en la anterior, no se restringía la inscripción de contratos por cotas". Documento suministrado por LINA MARÍA CÁRDENAS y Diego ARMANDo RuIZ.

Y aunque para entonces las dificultades técnicas y jurídicas para inscribir contratos con áreas otorgadas por cotas lograron ser resueltas, estas volvieron a surgir tras la implementación del Catastro Minero Colombiano (CMC) en el año 2007 y persisten en la actualidad, lo que ha impedido la inscripción de nuevos contratos de concesión y de las solicitudes de legalización de minería de hecho que han obtenido viabilidad técnico-minera y ambiental. Según explica BEATRIZ EugENIA GALLEGo, Ingeniera de Minas encargada de la Oficina de Asuntos Mineros de la Alcaldía de Marmato, la nueva dificultad se origina en que anteriormente el estudio de área se hacía de forma manual, pero tras la adopción del CMC se efectúa a través de una plataforma que no permite inscribir solicitudes de registro por cotas: entrevista, 7 de marzo de 2012.

43 Cabe señalar que, a la fecha, el contrato CHG-081 no cuenta con Plan de Manejo Ambiental, pues Minerales Andinos de Occidente, titular del 89\% de los derechos de explotación, renunció a la solicitud de legalización ambiental argumentando la dificultad para llegar a acuerdos con los demás titulares del contrato. Corpocaldas, exp. 1381, fols. 111, 143 y 146-148, y fol. 3 del Plan de Manejo Ambiental anexo a este expediente. 
realidad que seguía estando ordenada por relaciones productivas y sociales basadas en el ejercicio de la pequeña minería.

\subsection{1-2015: ¿queda un lugar para la pequeña minería?}

Finalmente, la legislación expedida en lo que va corrido del siglo XXI consolida aún más la tendencia a identificar el desarrollo minero con la explotación a gran escala, suprimiendo los espacios legales para el ejercicio de la pequeña minería, lo que en el caso de Marmato se traduce en una crisis del modelo de distribución del territorio y de los derechos sobre el recurso aurífero establecidos en la legislación expedida cuando promediaba el siglo $\mathrm{XX}^{44}$.

Además del desmonte del sistema de aportes y la consiguiente liquidación de las empresas estatales encargadas de la administración directa del recurso aurífero, el Código de Minas de 2001 (Ley 685) eliminó la distinción conceptual entre pequeña, mediana y gran minería y, de este modo, la posibilidad de mantener espacios y establecer reglas de juego diferenciadas para cada una de ellas. Es verdad que la actual normatividad reconoce la existencia de "minería tradicional" 45 , estableciendo algunos espacios legales para su ejercicio a través de la declaratoria de zonas de reserva para el desarrollo de proyectos mineros especiales y de desarrollo comunitario ${ }^{46}$, las zonas mineras para grupos étnicos ${ }^{47}$ y la apertura de nuevos procesos de legalización para quienes adelanten explotaciones sin título minero ${ }^{48}$. Pero lo cierto es que dichas normas

44 Este modelo se plasma en el Plan Nacional para el Desarrollo Minero, visión al año 2019 (UPME, 2006), al igual que en los Planes de Desarrollo de los gobiernos de Álvaro Uribe y Juan Manuel Santos. Su concreción legislativa ha tenido lugar, principalmente, a través de las leyes 685 de 2001, 1382 de 2010 (esta última declarada inexequible en sentencia C-366/2011, aunque con efectos diferidos por dos años). Para un análisis de este modelo de desarrollo minero ver Fierro Morales, 2012: 45-67; Lasso Lozano, 2011: 95-131.

45 Definida como "aquella que realizan personas o grupos de personas o comunidades que exploten minas de propiedad estatal sin título inscrito en el registro minero nacional y que acrediten que los trabajos mineros se vienen adelantando en forma continua durante cinco (5) años, a través de documentación comercial y técnica, y una existencia mínima de diez (10) años anteriores a la vigencia de esta ley" (art. 1 de la Ley 1382 de 2010, que adiciona el art. 16 de la Ley 685 de 2001).

46 Arts. 31 y 248 a 250 del Código de Minas.

47 Arts. 121 a 136 del Código de Minas.

48 En la última década se han abierto dos procesos: uno en 2002, amparado en el artículo 165 del Código de Minas, reglamentado por el Decreto 2390 de 2002, que fue calificado como un "gran fracaso" por la Defensoría del Pueblo, señalando que, de 3.631 solicitudes presentadas a mayo de 2007, tan solo se logró la firma de 23 contratos de concesión: Defensoría del Pueblo, 2010: 12. El segundo proceso de legalización inició en el segundo semestre de 2010, en virtud del artículo 12 de la Ley 1382 de 2010, reglamentado por el Decreto 2715 de 2010. Cabe señalar, sin embargo, que el Ministerio de Minas mantuvo suspendidos los términos para recibir propuestas 
parecen tener una vocación de eficacia más simbólica que instrumental, en el sentido de que sirven al propósito de legitimar un nuevo modelo de desarrollo minero, al mostrar que en la Colombia minera del siglo XXI todavía queda un espacio para la pequeña minería tradicional. Sin embargo, al indagar por los requisitos para su puesta en marcha se encuentra que tales espacios de legalización dependen de condiciones que difícilmente se dan en la práctica, tales como la existencia de áreas libres para otorgar; la realización de diversos estudios que requieren del acceso a conocimiento experto, tecnologías y formas organizativas fuera del alcance de muchas de las comunidades que desarrollan pequeña minería; exigencias probatorias que no se corresponden con las condiciones de informalidad en las que buena parte de los mineros tradicionales desarrolla su actividad, o cumplimiento de plazos que desbordan la capacidad de gestión no solo de las instituciones estatales sino de las propias comunidades (Defensoría del Pueblo, 2010: 26). Los anteriores son tan solo algunos de los factores que frustran el propósito declarado de abrir alternativas reales para el desarrollo legal de la pequeña minería y hacen que en este punto cobren pleno sentido las palabras de Mauricio García Villegas al introducir la pregunta por las funciones no declaradas que también cumple el derecho:

El problema fundamental no se limita entonces a la pregunta por las causas del fracaso del derecho, sino más bien a la cuestión de saber en qué medida dicho fracaso responde mejor a un juego de poder dentro del cual el derecho cumple una función determinante. De esta manera, el asunto no es que el derecho choque con la realidad que se resiste al cambio y por esto resulta ineficaz; es más bien que la realidad no cambia porque choca con la resistencia del derecho, el cual persigue por sí mismo la ineficacia (García Villegas, 1993: 82).

Algo más eficaces se han mostrado, en cambio, las normas encaminadas a sancionar el ejercicio de la minería ilegal, cuya cantidad y severidad ha aumentado como resultado del interés estatal por enfrentar una actividad que en los últimos años, coincidiendo con el aumento en los precios del oro, se ha convertido en importante fuente de financiación para los grupos armados ilegales y refugio de capitales procedentes del narcotráfico (Defensoría del Pueblo, 2010: 26-28; Giraldo Ramírez y Muñoz Mora, 2010: 86-96) ${ }^{49}$.

de contratos de concesión y de legalización de minería de hecho entre febrero de 2011 y mayo de 2012 (Resols. 180099 de 2011, 181233 de 2011, 1810128 de 2012 y 180505 de 2012).

49 Además de las normas incluidas en el Código Penal, en los últimos años se han adicionado disposiciones sancionadoras principalmente a través de las leyes 1333 de 2010 (régimen sancionatorio en materia ambiental) y 1450 de 2011 (Plan Nacional de Desarrollo 2010-2014). Asimismo, varias de las disposiciones del proyecto de reforma al Código de Minas que se dis- 
El incremento de estas medidas represivas ha corrido de manera paralela al aumento de la conflictividad social, debido a la llegada de grandes empresas que han logrado la adjudicación de contratos de concesión en zonas donde la población local tradicionalmente ha ejercido la minería en condiciones de informalidad (Defensoría del Pueblo, 2010: 13). Las compañías recién llegadas obtienen una importante ventaja en términos jurídicos, ya que pueden hacer uso de los mecanismos sancionadores para expulsar o fijar las condiciones a las que deben ceñirse los mineros locales para continuar ejerciendo su actividad en áreas donde estos últimos no cuentan con un título que ampare su derecho a explotar, pero respecto de las cuales los mineros locales invocan el derecho que les confiere el ser oriundos del lugar y poseedores de las minas que ahora reclaman sus nuevos titulares.

Como era de esperarse, Marmato no fue ajeno a las transformaciones en la política y la legislación minera antes descritas. La precoz iniciativa de la Corona Goldfields de realizar un proyecto de explotación a cielo abierto fue retomada en 2005 por una nueva multinacional, que desde entonces ha hecho presencia en el territorio de Marmato a través de diversas compañías, hoy integradas como subsidiarias del Grupo Empresarial Gran Colombia Gold Corp $\left(\mathrm{GCG}\right.$, en adelante) ${ }^{50}$. Desde entonces, a través de negociaciones directas con los titulares de los contratos en virtud de aporte suscritos a comienzos de los años 90, del Registro de Propiedad Privada 357 de Echandía, del contrato CHG-081 y de los contratos de legalización de minería de hecho suscritos en 1998, la nueva compañía (a través de sus filiales) logró hacerse al control de 84 de los 118 títulos mineros que aparecen registrados en el municipio, entre ellos del contrato 014-89M que autoriza a Mineros Nacionales S.A. (hoy subsidiaria de la GCG) a explotar la parte baja del cerro de Marmato $^{51}$. Recientemente, con el objeto de ir ajustando los derechos adquiridos al tipo de explotación

cute en la actualidad adicionan o modifican normas penales relacionadas con el ejercicio de la minería. También el gobierno colombiano adelanta conversaciones en el seno de la Comunidad Andina de Naciones (CAN) para suscribir una política conjunta de lucha contra la minería ilegal: ver http://m.semana.com/nacion/delegados-can-aprueban-politica-conjunta-contra-mineria-ilegal/180236-3.aspx última consulta: 22 de julio de 2012.

50 Entre las sociedades hoy pertenecientes a este grupo empresarial que han hecho presencia en Marmato se destacan, en orden de aparición, Colombia Goldfields Ltd., Compañía Minera de Caldas S.A.S., Minerales Andinos de Occidente S.A., Minera Croesus S.A.S., Gavilán Minerales S.A.S. y Medoro Resources. La composición del Grupo Empresarial Gran Colombia Gold Corp. se estableció a través de la consulta del Certificado de Existencia y Representación Legal de una de sus subsidiarias, Minerales Andinos de Occidente S.A., expedido el 20 de junio de 2012, donde se muestra que la integración de estas y otras sociedades al mencionado grupo se realizó a través de documento privado suscrito el 2 de febrero de 2012.

51 Según datos suministrados por la Delegación Minera de Caldas en oficio UDM 3485 del 21 de noviembre de 2011. 
que pretende desarrollar, la GCG (a través de su filial Minerales Andinos de Occidente) solicitó la integración de buena parte de los contratos de pequeña minería que hoy tiene en la zona alta de Marmato en un área unificada, conforme a lo establecido en el artículo 101 del Código de Minas. Esta petición fue aprobada por la Secretaría de Gobierno de Caldas en Resolución 2188 de 10 de mayo de 2011, por la cual se autoriza la integración de 54 títulos mineros ubicados en la zona alta del cerro El Burro; decisión que altera de manera significativa la escala a la que se autorizan las operaciones en dicha zona, toda vez que obliga a la empresa a presentar un programa único de explotación y, una vez autorizado este, a la suscripción de un nuevo contrato de concesión.

Este paulatino cambio en la composición de la propiedad minera en Marmato ha tenido importantes consecuencias sociales y económicas, derivadas del conflicto entre la compañía y muchos de los mineros que tradicionalmente han ejercido su labor en la zona alta, quienes con la creciente concentración de los derechos de explotación en manos de la primera han visto amenazada su fuente de trabajo y truncada la posibilidad de legalizar su actividad de manera autónoma. En esta confrontación es posible identificar al menos tres momentos:

En los primeros años (2005-2007), la estrategia adoptada por la compañía -que para entonces hacía presencia en la zona como Compañía Minera de Caldas y Colombia Goldfields- fue proceder al cierre de las minas y a la destrucción de algunos de los molinos e inmuebles adquiridos en la parte alta de Marmato, bajo el argumento de la contaminación que producía la minería de pequeña escala (Ramírez Guerrero, 2010: 90). Esto generó un fuerte rechazo por parte de los marmateños quienes, además de sentirse agredidos por una manifestación de poder que evocaba los aciagos tiempos de Vásquez Cobo, por la descalificación de su manera de ejercer la minería y por la destrucción de bienes que consideran parte de su patrimonio cultural, se vieron privados de su principal fuente de trabajo.

Este período coincidió con la ocurrencia en mayo de 2006 de lo que algunos describieron como una "avalancha" y otros como la caída de un "flujo de lodos y estériles" sobre la zona de la antigua plaza y del hospital, lo que dio lugar a la declaratoria de calamidad y emergencia en el municipio por parte del gobierno nacional, al abandono de las zonas directamente afectadas por el deslizamiento (argumentando la imposibilidad jurídica de invertir recursos públicos en zonas de riesgo), y precipitó los planes para el progresivo traslado del casco urbano al sector de El Llano ${ }^{52}$. La incertidumbre sobre la

52 El tema del riesgo ha generado desde entonces opiniones encontradas, tanto en los diversos estudios técnicos que han sido realizados como entre los habitantes de Marmato, enfrentando a quienes consideran que el traslado del casco urbano es inevitable e incluso representa 
suerte del pueblo contribuyó a que muchos de los empresarios mineros que para entonces conformaban la élite local se decidieran a partir del pueblo tras vender sus minas, molinos y otras propiedades a la compañía; lo propio hicieron muchos de los trabajadores que fueron despedidos luego del cierre de las minas, quienes emigraron en busca de empleo hacia otras regiones mineras del país ${ }^{53}$. A su vez, otros pobladores emprendieron iniciativas de resistencia tanto al traslado del pueblo como a la realización del proyecto de gran minería a través de diversas organizaciones comunitarias que convergieron en la creación en 2006 del Comité Cívico Pro Defensa de Marmato el cual, entre otras acciones, lideró la conformación de convites para limpiar la plaza de los escombros y estériles caídos en el evento de mayo de $2006^{[54]}$.

En un segundo momento (2008-2010) tuvo lugar un reacomodo de las estrategias productivas de los marmateños para hacer frente al cierre de muchas de las pequeñas empresas mineras que venían operando en la parte alta de Marmato. Los mineros cesantes que permanecieron en el pueblo comenzaron a incursionar en las minas clausuradas por la empresa, dando origen al fenómeno del "guacheo" que se extendió en este período, debido a la llegada de gente procedente de municipios vecinos y de otras zonas del país, atraída por la posibilidad de probar suerte en unas minas sobre las que ni sus nuevos dueños ni el Estado ejercían ningún control ${ }^{55}$. A ello se sumó la intensificación

una oportunidad de progreso y quienes, por el contrario, enfatizan que el riesgo es mitigable si se realizan las obras correspondientes, e interpretan la negativa a efectuarlas como una prueba más del desinterés del Estado por el municipio y su preferencia por allanar el camino al proyecto de gran minería que pretende adelantar la multinacional, en tanto el argumento del riesgo torna ineludible el traslado del municipio e implica que sus costos deban ser asumidos (al menos en parte) con recursos públicos (RAMÍREZ GUERRERO, 2010; LASSO LOZANO, 2011: 145-170; GONZÁLEZ COLONIA, 2012: cap. 3, 11-13; SANDOVAL y LASSO, 2012).

53 Entrevista a MAURicio CASTAÑEda, integrante de la Asociación de Mineros Tradicionales de Marmato, 31 de marzo de 2012.

54 Entrevistas a don Yamil Amar Cataño, Presidente del Comité Cívico Pro Defensa de Marmato, 30 de marzo de 2012, y a don Luis HERNANDo Álvarez, fundador y uno de los más activos integrantes del Comité, 22 de marzo de 2012.

55 Tradicionalmente la expresión "guachar" fue empleada entre los marmateños para referirse a la extracción de mineral de la veta, donde la roca es blanda, sin valerse de medios técnicos como taladros o explosivos. "Guachero" era el minero que, por carecer de medios para perforar o dinamitar la roca, se limitaba a arañar las partes blandas de la veta o a recoger la roca que otros ya habían aflojado y meterla en costales que, una vez completada la carga, denominan "guacha" (GonZÁLEZ COLONIA, 2012: cap. 3, 8-9). Tras la ocupación de las minas abandonadas por la compañía, la expresión se generalizó para denominar la actividad ejercida por los pequeños grupos de mineros que, de manera independiente y al margen de cualquier relación laboral, comenzaron a explotar estas minas, incorporando en algunos casos el uso de perforadoras y explosivos, o a iniciar la apertura de nuevos frentes de trabajo en la parte alta del cerro. Aunque algunos habitantes de Marmato emplean la expresión "guachero" con una connotación peyorativa 
de la crisis económica en el municipio, a raíz del cese de operaciones de la Colombia Goldfields y la Compañía Minera de Caldas, que abandonó el pueblo dejando pasivos laborales y deudas con los comerciantes locales, lo que llevó a algunos de los nuevos desempleados a buscar el sustento en la guacha (Lasso Lozano, 2011: 162). Para finales de 2009, el proyecto de gran minería fue reasumido por la compañía Medoro Resources, que asumió el control de la explotación de Mineros Nacionales en la zona baja de Marmato, y en el segundo semestre de 2010 inició operaciones de mediana minería subterránea en algunas de las minas de la parte alta, situadas en el sector de Echandía.

El tercer momento (2011-2012) representa un cambio en la imagen y en la estrategia adoptada por la compañía para ganarse el favor de la comunidad de Marmato y gestionar el conflicto con los pequeños mineros de la zona alta. Para mediados de 2011, Medoro Resources salió de escena y la Gran Colombia Gold pasó a ocupar su lugar. Esta última intensificó sus esfuerzos por ganarse la licencia social para operar, tratando de tomar distancia y enmendar los errores de las compañías anteriores a través de la suscripción de convenios de inversión social con la administración municipal, el apoyo a algunos proyectos productivos e iniciativas comunitarias, los cuales acompañó de un amplio despliegue en los medios de comunicación. Frente a los mineros de la zona alta, la compañía ha implementado una estrategia que combina el recurso a medios represivos y persuasivos: los primeros apuntan a recuperar el control de las minas mediante el recurso a amparos administrativos, denuncias penales e incluso el desalojo directo de algunas de las minas a través de la acción conjunta de la fuerza pública y de la compañía de vigilancia privada que presta seguridad a la compañía ${ }^{56}$. Los segundos consisten en mejorar

(que asocian al carácter poco tecnificado, ilegal y desordenado de esta forma de explotación), quienes se dedican a esta actividad reivindican esta denominación, a la que asocian una connotación de resistencia a la multinacional y defensa de la minería tradicional. Así lo expresa MAURICIO CASTAÑEDA, líder de la mina La Socorro: "dicen que suena muy feo, pero si me preguntan ‘usted qué es?', yo soy guachero. Pero como dicen que guachero es ilegal entonces ahora lo llaman minero tradicional o pequeño minero. Pero a lo que es, es, yo a lo blanco lo llamo blanco y a lo negro, negro. Para mí guachero... me siento orgulloso de ser guachero. Hace 6 años estoy guachando, directamente": entrevista, 31 de marzo de 2012.

56 A raíz de uno de estos intentos de desalojo, ocurrido en enero de 2011, se conformó la Asociación de Mineros Tradicionales de Marmato, que agrupa alrededor de 500 pequeños mineros o "guacheros" que ejercen su actividad en 15 de las minas adquiridas, y luego clausuradas, por la compañía en la zona alta de Marmato. Además de la resistencia al desalojo de las minas y al proyecto de gran minería, la Asociación de Mineros Tradicionales intenta llevar a cabo una ordenación de la explotación del recurso en cada una de las minas que controla, a través de la definición de normas básicas de funcionamiento definidas en asamblea (general o por minas) y que el líder de cada mina se encarga de hacer cumplir. Entrevistas a MARIO TANGARIFE, Presidente de la Asociación de Mineros Tradicionales de Marmato, 16 de marzo de 2012, y a MAURICIO CASTAÑEDA, líder de la mina La Socorro, 31 de marzo de 2012. 
las ofertas de compra a los pocos que aún no han vendido sus derechos de explotación (o de indemnización para poseedores sin título), invitándoles a suscribir contratos de operación y, más recientemente, a sentirse dueños del proyecto a través de la oferta de paquetes de acciones a las asociaciones de mineros y otros grupos organizados de población ${ }^{57}$.

Así las cosas, ante la inexistencia de áreas libres para otorgar y la inoperancia que han demostrado los programas de legalización de minería de hecho implementados en la última década, la única posibilidad que hoy se plantea a los mineros de la zona alta que no cuentan con un título que ampare su actividad es suscribir contratos de operación con la compañía, alternativa a la que muchos mineros se rehúsan porque implica un derecho apenas temporal a permanecer en las minas, a condición de reconocer a la firma como única titular del derecho de explotación y asumir el cumplimiento de todas las obligaciones legales vinculadas al ejercicio de la actividad minera, algunas de las cuales, según argumentan, exceden su capacidad técnica y económica ${ }^{58}$. Entretanto, algunos de los pequeños empresarios mineros que negociaron sus derechos con la compañía han aceptado suscribir estos contratos de operación, porque ello les permite "coger unos pesos", tener la tranquilidad de permanecer explotando las minas por un tiempo y acceder a los explosivos necesarios para la explotación; insumo que, de otro modo, resulta muy difícil conseguir, debido a las crecientes restricciones impuestas a la venta de dichos materiales ${ }^{59}$.

Con todo, la distribución del territorio entre zona alta y baja no solo se ha visto alterada en la superficie por la adquisición de títulos, la integración de

57 La oferta de negociar con los mineros, tengan o no título sobre las minas en las que laboran, está generando efectos adversos tanto para la compañía como para los pequeños mineros que tradicionalmente han ejercido su actividad en la parte alta de Marmato, pues ella está alentando que cada vez más se abran nuevos huecos en la montaña por parte de personas que pretenden de este modo generar una situación que les permita negociar con la compañía. Esto, además de elevar los costos sociales del proyecto para la compañía, ha incrementado los conflictos con los pequeños mineros asentados de tiempo atrás en la parte alta del cerro.

58 Buena parte de los mineros que se niegan a aceptar la firma de estos contratos pertenecen a la Asociación de Mineros Tradicionales de Marmato. JHON Fredy MuÑoz, uno de sus líderes, explica que las condiciones impuestas en los contratos de operación resultan inaceptables para ellos: la primera, porque implica reconocer a la compañía un derecho sobre las minas, el cual desconocen argumentando que, tras adquirirlas, la compañía procedió a su cierre y abandono, lo que sería causal para declarar la caducidad de los contratos de explotación de acuerdo a la legislación minera y daría a sus actuales ocupantes el derecho a explotarlas. La segunda, porque se trata de un contrato muy exigente, que implica desarrollar una minería tecnificada y cumplir con toda la normatividad ambiental y minera, lo cual excede las posibilidades económicas de los pequeños mineros. Entrevista, 3 de marzo de 2012.

59 Según lo explica don Alberto Valencia, minero de Echandía, en entrevista realizada el 22 de marzo de 2012. 
áreas y el inicio de labores de explotación por parte de la multinacional en algunas de las minas adquiridas en la parte alta de Marmato. Esta división territorial también se ha visto socavada por debajo, desde los cimientos del cerro El Burro. El volumen de la explotación subterránea que esta compañía desarrolla en la parte baja, a través de su filial Mineros Nacionales, ha ido escalando hasta conectarse con algunas de las minas que se encuentran sobre la cota 1.260, la que marca la división entre zona alta y baja, eliminando una franja o "machón de seguridad" que garantiza a los mineros y demás habitantes de la parte alta del cerro que sus minas no van a ser desfondadas y que su pueblo no va a colapsar. Como lo explicaba un concejal en una reunión realizada en junio de 2010, en la que se discutía ese problema con representantes de la compañía:

... esa situación del machón de seguridad únicamente la hemos manejado nosotros en nuestra cultura, porque ninguna ley dice que hay que dejar un machón de seguridad, y de eso se pega Mineros Nacionales y su gerente para decir que ellos no están obligados a dejar machón de seguridad. O sea que el día menos pensado van a vaciar a San Pedro, vacían la Cincomildoscientos y vacían todo y quedamos sobre el aire todos (citado por González Colonia, 2012: cap. 3, 16-17).

Pero el límite ya ha sido franqueado. Lo que era apenas un temor fundado en 2010 es una realidad en la actualidad, como lo evidencia lo ocurrido con la mina Cincomildoscientos, hoy propiedad de la compañía, y una de las primeras que ocuparon los guacheros a fin de evitar que fuera "vaciada" y convertida en boca de ventilación para la salida de los gases que se originan en la planta de Mineros Nacionales. Los guacheros no lograron su propósito y hoy, cuando se baja del pueblo por la carretera, en dirección sur, metros antes de llegar a la quebrada Cascabel, una fuerte bocanada de aire caliente, impregnado de gases, sale a la superficie por la antigua bocamina de la Cincomildoscientos, como testimonio de esta primera batalla perdida en el intento de evitar que la empresa horadase la parte alta del cerro, que los pequeños mineros de Marmato reclaman como suya ${ }^{60}$. Pero también en el costado opuesto los

60 En este orden de ideas, algunos sugieren que mientras la gente anda ocupada en la oposición al proyecto a cielo abierto, el verdadero proyecto (ya iniciado) es otro: "uno no ve una cultura del open pit, sino seguir por socavón desde Mineros Nacionales y comerse la montaña hacia arriba. Todos estamos concentrados en lo que pasa arriba, pero la verdadera explotación está abajo. Pero es imposible estar allá. Es como discutir con alguien sobre la propiedad de un banano, mientras uno de los que discute se come el banano. En Marmato hay una empresa seria que es Mineros Nacionales, no para un solo día, consume muchos explosivos. Yo siento que está pasando lo mismo que en esa película 'La estrategia del caracol'. De modo tal que mientras se adelanta el pleito se están llevando la casa por debajo. Con el precio actual del oro una explota- 
mineros del sector de Cien Pesos, situado en la salida del pueblo en dirección norte, expresan su preocupación debido a que el doble frente de explotación subterránea que en la actualidad adelanta la compañía terminará por dejarlos sin minas, pues según explica don Yamil Amar Cataño: "Yo tengo una de las minas en Cien Pesos y nos vamos a quedar sin nada. Dicen que van a hacer una clavada para comunicar la mina de Echandía con la de Mineros y con eso nos dejan sin mina. Allá sí es por obligación que hay que vender" ${ }^{61}$.

\section{En definitiva, ¿qué queda del régimen especial para Marmato?}

Ante este panorama de transformaciones legislativas, decisiones administrativas y avances en la explotación que han modificado de manera significativa el mapa de la propiedad minera en Marmato, facilitando su concentración en un solo gran actor que pretende variar la escala en la que tradicionalmente se ha llevado a cabo la explotación, es preciso volver a la pregunta inicial: ¿qué queda del régimen especial para Marmato definido en la legislación expedida entre 1946 y 1954 ?

Para responder a esta cuestión es preciso identificar los tres elementos centrales que estructuran este régimen: (1) una institucionalidad específica encargada de la ordenación directa del recurso minero, primero en cabeza del Director y luego del Administrador de las Minas Nacionales de Marmato; (2) unas reglas específicas de contratación, basadas en el sistema de pequeños contratos de laboreo en participación para la zona alta y contratos de concesión para la zona baja; (3) la distribución del territorio del cerro El Burro y del sector de Cien Pesos entre una zona alta, reservada a la pequeña minería, y una zona baja para la explotación a mediana escala.

Ya se ha indicado cómo la reestructuración de la institucionalidad minera ocurrida en las últimas tres décadas condujo a la transformación y posterior liquidación de las entidades encargadas de la administración directa de las minas nacionales, lo que implicó la desaparición del primero de los elementos que sostenían el régimen especial.

En cuanto al segundo de estos elementos, las normas relativas a la contratación, un examen de su vigencia desde un punto de vista jurídico formal enseña que ninguna de ellas fue objeto de derogación expresa por la legislación general expedida con posterioridad. Por otra parte, de acuerdo con los criterios de resolución de antinomias previstos en nuestro sistema jurídico,

ción subterránea es rentable": entrevista a ALEXANDER RESTREPO, abogado experto en derecho minero, 9 de abril de 2012.

61 Entrevista a Yamil Amar Cataño, Presidente del Comité Cívico Pro Defensa de Marmato y reconocido empresario minero de la zona alta, 30 de marzo de 2012. 
no existe claridad respecto a si una norma especial anterior (en este caso las contenidas en el Decreto 2223 de 1954) pueda ser derogada tácitamente por una norma general posterior con la que aquella resulte incompatible ${ }^{62}$. Como quedó en evidencia en el análisis efectuado en este epígrafe, la interpretación que se impuso tras la expedición del Código de 1988 fue aquella que hizo a un lado el régimen contractual especial que hasta entonces había regido la relación entre el Estado y los mineros de Marmato, para aplicar en su lugar la normatividad general; todo ello a tono con la progresiva deslocalización de la autoridad minera y la consecuente tendencia a la estandarización y formalización de los contratos. Con todo, el artículo 356 del Código de Minas de 2001 dejó a salvo la vigencia de los contratos suscritos al amparo del régimen especial, al señalar:

Los contratos celebrados sobre las zonas de la reserva especial de Muzo, Coscuez y Peñas Blancas, para explorar y explotar esmeraldas, de las de Marmato, Supía, Distritos Vecinos, Guamo o Cerro Marmato y Cien Pesos para explorar y

62 Cabría afirmar que en este caso se presenta una antinomia de segundo grado entre el criterio de especialidad, según el cual, en caso de incompatibilidad, se debe preferir la disposición relativa a un asunto especial sobre la que tenga carácter general (art. 5. ${ }^{\circ}$, num. 1 de la Ley 57 de 1887), y el criterio cronológico, según el cual la ley posterior prevalece sobre la anterior (art. 2. ${ }^{\circ}$ de la Ley 153 de 1887). Para el tema que nos ocupa, algunos de los principales puntos de incompatibilidad entre el régimen contractual para las minas de Marmato y la legislación general posterior versan sobre el monto de las regalías y otros derechos de participación del Estado, la duración de los contratos y la obligación de registrarlos (que implicaba eliminar la superposición de áreas y someterlos a formalidades que hasta entonces no habían caracterizado las relaciones contractuales entre el Estado y los mineros de la zona alta de Marmato). De acuerdo con el criterio de especialidad, en caso de antinomia tendría que darse aplicación preferente al régimen contractual previsto en el Decreto 2223 de 1954; según el criterio cronológico, en cambio, las normas posteriores, aunque generales, tendrían preferencia sobre las especiales.

La Teoría del derecho presenta este tipo de conflictos como el clásico ejemplo de antinomias de segundo grado, que se resuelven reabriendo en cada caso el balance de razones sustantivas y optando por la solución que mejores argumentos tenga a su favor; ello salvo que el sistema jurídico disponga de una regla de tercer grado que establezca la prevalencia, en abstracto, de uno de los criterios formales de resolución de antinomias sobre su contrario (BoBBIO, 1980: 361-362). Cabría preguntarse si, en nuestro ordenamiento, el artículo 3. ${ }^{\circ}$ de la Ley 153 de 1887 , en tanto establece que una disposición legal se estima insubsistente "por existir una ley nueva que regule íntegramente la materia a la que la anterior disposición se refería", representa una regla de tercer grado que resuelve la antinomia que se plantea en casos como este, a favor de la aplicación de la norma general posterior, siempre que esta regule íntegramente la materia tratada en la norma especial anterior. La Corte Constitucional ha dado aplicación a este criterio en la sentencia C-241 de 2010, al considerar insubsistente una norma legal expedida en 1905 que regulaba el lanzamiento por ocupación de hecho en predios rurales, bajo el argumento de que esta había sido modificada por normas posteriores y subrogada por una ley posterior, el Código Nacional de Policía expedido en 1970, que regulaba íntegramente las acciones para impedir la perturbación de la posesión o tenencia de un bien. 
explotar metales preciosos y sobre las salinas marítimas y terrestres, continuarán vigentes por el término acordado incluyendo sus prórrogas vigentes al momento de expedición de este Código. Terminados dichos contratos estas minas y salinas se contratarán mediante el sistema general de concesión, previos los trámites de licitación o concurso previstos en el artículo 355 anterior, si en dichas áreas se hubieren efectuado inversiones estatales de cualquier clase y cuantía.

Queda aún por responder la pregunta por la vigencia del tercero de los elementos sobre los que se apoyaba el régimen especial, esto es, la división entre la zona alta y baja del cerro, y su destinación para la pequeña y mediana minería, respectivamente, establecida inicialmente en los artículos $1 .^{\circ}$ y $2 .^{\circ}$ de la Ley 66 de 1946 y retomada luego en los artículos $1 .^{\circ}$ y $2 .^{\circ}$ del Decreto 2223 de 1954. Además de no haber sido objeto de derogación expresa, desde un análisis puramente formal cabe señalar que esta distinción se mantiene vigente en tanto no resulta necesariamente incompatible con la legislación expedida con posterioridad, con lo cual no hay lugar a la existencia de antinomias; en segundo lugar, los contratos aún vigentes celebrados tanto en la zona alta como en la zona baja de Marmato delimitan las áreas otorgadas en concesión y la escala de explotación (pequeña o mediana) que autorizan a realizar tomando como referente esta división territorial; finalmente, existen conceptos específicos de la autoridad minera que afirman la vigencia de las normas que establecieron tal distribución del territorio y de los derechos de explotación ${ }^{63}$.

Sin embargo, vale la pena recordar que, de acuerdo con lo establecido en el artículo 2. ${ }^{\circ}$ del Decreto 2223 de 1954, desde entonces el legislador extraordinario dejó abierta la posibilidad de modificar este régimen de distribución de los derechos de explotación para otorgarlo a una sola gran empresa, tal y como viene ocurriendo en la actualidad (aunque bajo condiciones contractuales diferentes de las allí previstas).

En este punto, y para enlazar con la pregunta de investigación que motivó nuestra llegada a Marmato, surge la cuestión de si, a la luz de las normas que garantizan el derecho de los ciudadanos a la participación, y en un contexto pluriétnico como el que se presenta en este municipio, la modificación de este régimen de ordenación del territorio y de distribución de los derechos de explotación puede ser una decisión unilateral de la autoridad minera o, por el contrario, está sometida a la exigencia de consulta previa. Pero un adecuado

63 En oficio 101403678 del 2 de mayo de 2000, en respuesta a una petición en la que se indaga por la vigencia del Decreto 2223 de 1954, MINERCOL conceptúa que sus artículos $1 .{ }^{\circ}$ y 2 . $^{\circ}$ permanecen vigentes, señalando en cambio que otras normas relativas al régimen de contratación (como los artículos $6 .^{\circ}$ y 12 ) habían sido modificados o derogados por normas posteriores. Documento suministrado por el abogado DiEgo ARMANDo RuIZ. 
planteamiento de esta cuestión requiere antes indagar de qué manera este modelo de distribución ha estructurado la relación que los habitantes de Marmato han construido con el espacio y forjado su identidad como pueblo minero.

\section{Territorialidad vertical como condición para un orden social y económico (algo) menos vertical}

Figura 3. Cartografía del cerro El Burro y sectores aledaños

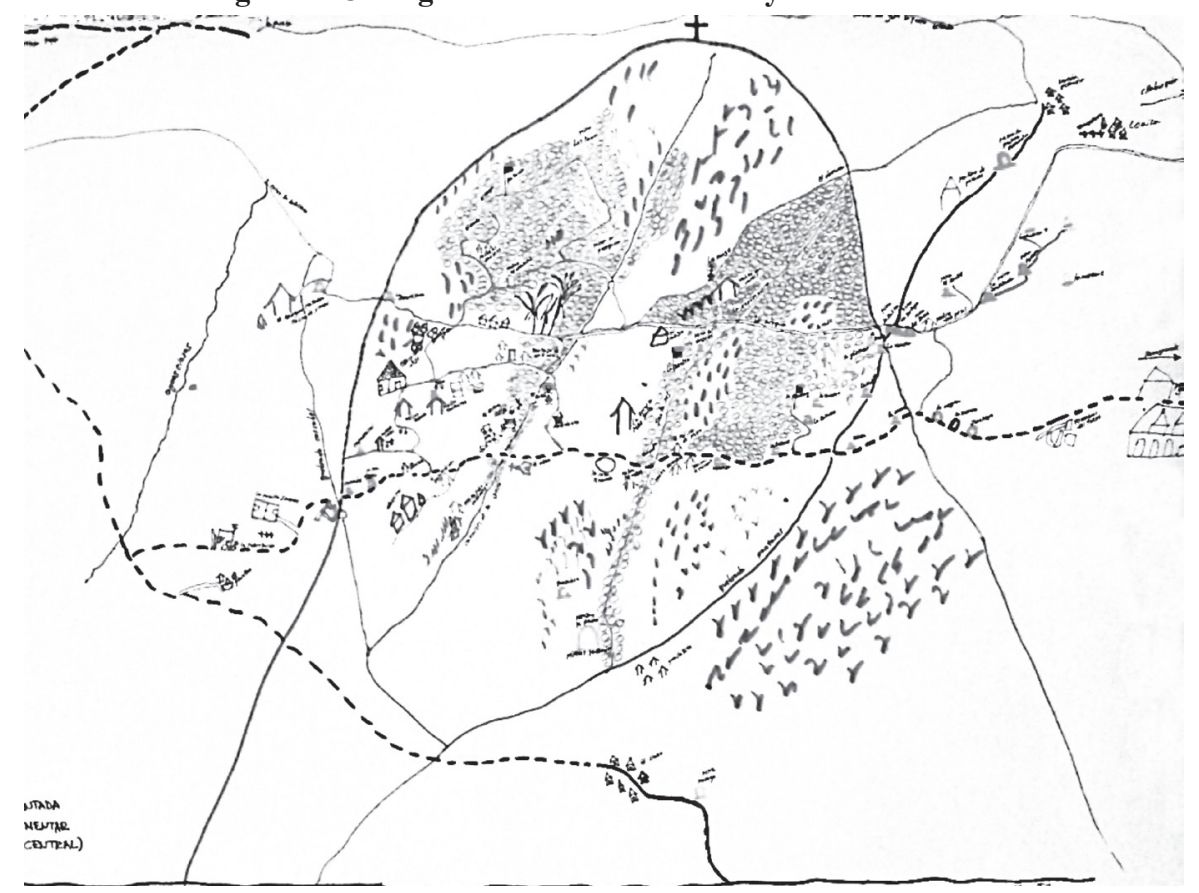

Elaborada por Mauricio Castañeda, minero tradicional de Marmato.

Establecida la vigencia de las normas que posibilitaron la coexistencia de la pequeña y mediana minería en el municipio, interesa ahora destacar cómo esas normas estructuraron una configuración territorial que los marmateños insisten en defender en la coyuntura actual, cuando, debido al aumento de los precios del oro y de otras circunstancias actúan como combustible de la llamada "locomotora minera", ha vuelto a actualizarse la tensión entre un modelo eficientista que entregue el monopolio de la explotación del recurso a las grandes empresas y un modelo de explotación del recurso que deje espacio y reconozca la importancia de la minería tradicional.

Desde la geografía se concibe el territorio como "un concepto relacional que insinúa un conjunto de vínculos de dominio, de poder, de pertenencia o de apropiación entre una porción o la totalidad de espacio geográfico y un 
determinado sujeto individual o colectivo". Así definido, el territorio implica una relación entre un sujeto (individual o colectivo) y un objeto (espacio geográfico), en virtud de la cual el primero establece sobre el segundo vínculos de propiedad, lazos subjetivos de identidad y afecto, con lo cual este constituye un "espacio geográfico revestido de las dimensiones política, identitaria y afectiva, o de todas ellas" (Montañez Gómez, 2001: 21-22). Pero también la noción de territorio implica la existencia de un "otro", con el cual de disputa, se comparte o se negocia la posesión y posición de ese espacio representado y apropiado como territorio (Segato, 2006: 77). Por su parte, se emplea la noción de territorialidad para designar "el conjunto de prácticas y sus expresiones materiales y simbólicas, capaces de garantizar la apropiación y permanencia de un territorio dado bajo determinado agente individual o social" (Montañez Gómez, 2001: 22).

Estas nociones sugieren la estrecha relación que existe entre la representación y apropiación de un espacio como territorio, el conjunto de prácticas, y sus expresiones materiales y simbólicas, que se emplean para tal efecto y definen la territorialidad, y la configuración de identidades y formas de vida, pues, como señala Rita Laura Segato, "el territorio es el escenario del reconocimiento; los paisajes (geográficos y humanos) que lo forman son los emblemas en que nos reconocemos y cobramos realidad y materialidad ante nuestros propios ojos y los ojos de los otros" (Segato, 2006: 77).

Para el caso que nos ocupa, la distribución vertical del cerro El Burro (y de los sectores aledaños) entre una zona alta y una baja constituye un elemento central de la apropiación y representación de este espacio como territorio y está presente en muchas de las prácticas, materiales y simbólicas, que definen la territorialidad. Además de la división de dos escalas de producción minera, pequeña y mediana, que se desarrollan en la zona alta y baja del cerro, respectivamente, ella está presente en otros elementos que estructuran las relaciones sociales y productivas que tienen lugar entre los marmateños:

La zona baja, cuyo referente principal es la planta de Mineros Nacionales, se identifica con el desarrollo de una minería industrial y tecnificada, que evoca el papel pionero que ya desde la legislación de 1939 se asignaba a la zona de La Palma; asimismo representa un lugar que garantiza empleo permanente para propios y extraños y relaciones de trabajo formales, con las ventajas (pago de prestaciones sociales, afiliación a salud y riesgos profesionales) e inconvenientes (cumplimiento de una jornada de trabajo más extensa, que incluye trabajo nocturno o en días festivos, sometimiento a un reglamento, ingresos estables pero globalmente inferiores a los que se obtienen trabajando por cuenta propia) que los mineros de Marmato asocian a la formalidad. Entretanto, la zona alta representa un espacio en el que se desarrollan relaciones económicas y laborales en un contexto de informalidad, pero a la vez, de 
menor asimetría, debido a la concurrencia de pequeños empresarios mineros que ofrecen trabajo a los mineros locales, lo que posibilita a estos últimos disponer de cierto margen de libertad para negociar las condiciones bajo las cuales aceptan trabajar para otro, pues, en última instancia, siempre queda la posibilidad de ir a buscar su sustento de manera autónoma, sin mediación de ningún patrono, en el bareque o en la guacha.

Este particular tejido de relaciones sociales y productivas distingue a Marmato de otros pueblos mineros que se desarrollan en torno a economías de enclave, dando lugar, en su lugar, a lo que la socióloga Melina Lasso, siguiendo a Bourdieu, ha denominado como un particular "habitus productivo" de los mineros de Marmato (Lasso Lozano, 201: 170-191) y el antropólogo Carlos Julio González designa, a su vez, como un "modo de producción" marmateño, fraguado en torno al ejercicio de la minería tradicional (González Colonia, 2012).

Tal modelo de distribución del espacio y del recurso minero entre una zona alta donde el oro es para los marmateños y demás pequeños mineros que vengan a buscar el sustento, siempre que acojan las reglas de convivencia establecidas por los marmateños, y una zona baja que el Estado puede contratar con empresas foráneas, que también han de cumplir con unas pautas de convivencia y respeto para ganarse su derecho a permanecer en Marmato y beneficiarse de sus riquezas, está firmemente arraigada en la manera en que los marmateños significan su relación con el entorno (González Colonia, 2012). Así lo evidencia la explicación que ofrece don Eulises Lemus sobre las razones del legislador para reservar la parte alta del cerro para la pequeña minería:

Este es el cerro, aquí está el Cauca. Arriba hay un depósito hidrotermal que nació por el levantamiento de un magma. Sube una placa que produce un levantamiento. Esto es caliente. Cuando llega a la altura entonces hay fracturamiento. Hay puras fracturas dentro de la roca. Después vino un fluido que pasó por esas fracturas y esas son las vetas. Arriba subió el de menor calidad. Por eso está dividido en etapas. Una es la zona baja, que el Estado mantuvo por tiempo como reserva nacional. Esa sería la más rica. Pero aquí el oro no está muy superficial sino interno. Por eso se lo entregó a una empresa multinacional, con capacidad.

La parte de abajo es más rica pero está profunda. $\mathrm{Al}$ ir subiendo el oro quedó más a la intemperie. Arriba merma la riqueza pero es más fácil sacarlo y cuanto más sube el oro es de menor ley pero es más fácil sacarlo, porque se saca por barequeo y por el término último que están empleando aquí "guacheo"... Marmato viene a estar en la mitad de montaña. Esta parte de arriba donde el oro es menos fino pero está más superficial, esa nos la dejó el Estado para que la trabajáramos ${ }^{64}$.

64 Entrevista a don Eulises Lemus, mineralogista marmateño, 3 de marzo de 2012. 


\section{CONCLUSIONES}

Esta mirada al pasado y al presente del régimen normativo especial para las minas de Marmato permite concluir que aún permanece vigente la distribución territorial entre zona alta y baja, destinadas al ejercicio de la pequeña y mediana minería, respectivamente, establecida inicialmente en la Ley 66 de 1946 y retomada luego por el Decreto 2223 de 1954. Asimismo, que esta distribución territorial se adoptó como una fórmula para resolver la problemática social y económica que se había generado a raíz de la entrega a un solo actor del derecho a explotar todo el oro del cerro de Marmato y sus alrededores, y a la vez conciliar la solución a esta problemática social con el interés en procurar una explotación eficiente del recurso aurífero. Tal distribución pudo pervivir durante el resto del siglo $\mathrm{XX}$, como resultado de un conjunto de circunstancias políticas y económicas que favorecieron (o al menos no obstaculizaron) el desarrollo de la minería a pequeña escala en esta zona del país.

Más allá de si las normas del Decreto 2223 de 1954 dejaban abierta la posibilidad de volver a un régimen de monopolio y contratar la explotación de todo el cerro con una sola empresa, lo cierto es que aquellas contribuyeron a estructurar una construcción de territorialidad que a su vez fue decisiva en la particular construcción de la identidad de Marmato como pueblo minero, que le hace diferente de otros que estructuran sus relaciones sociales y productivas en torno de una economía de enclave, dependiente de una gran empresa. Los marmateños, en cambio, han estructurado sus relaciones sociales y productivas a partir de una distribución del territorio que ha permitido la convivencia (no exenta de conflictos, por cierto) entre pequeña y mediana minería, logrando así mantener, por un lado, una fuente permanente y segura de empleo formal en la empresa de mediana minería situada en la zona baja, cuya técnica y volúmenes de explotación la aproximan a los criterios de eficiencia que pretende alcanzar el país minero. Pero a la vez, este modelo de distribución territorial ha permitido que sus habitantes no dependan por completo de esta empresa y, a través de los emprendimientos de pequeña minería en la zona alta, haya sido posible "la existencia de una categoría laboral, libre de controles estatales, que es fundamento de la idea marmateña de que en este pueblo minero el que no consigue dinero es porque no quiere trabajar, y de que aquí no hay desempleo ni se pasa hambre" (González Colonia, 2012, cap. II, 19). Esta territorialidad vertical ha posibilitado, en contraste, relaciones sociales y productivas algo menos asimétricas, condición que en parte explica que Marmato hasta ahora no se haya visto afectado por los estragos del conflicto armado interno, convirtiéndole en una excepción respecto de otros pueblos mineros de Colombia. 
La pregunta que queda es si las decisiones que autorizan la cesión de títulos mineros en la parte alta del cerro a una empresa que se propone adelantar un proyecto de gran minería podían adoptarse sin garantizar la adecuada participación de la población local y, particularmente, de los grupos étnicos que habitan el territorio. Lo anterior teniendo en cuenta que las mismas han afectado la distribución territorial y de los derechos de explotación del recurso sobre los que descansa la construcción de identidad de Marmato como pueblo minero. Una sentencia reciente de la Corte Constitucional (T-438 de 2015), en la que se tuteló el derecho a la consulta previa y al ejercicio de la pequeña minería tradicional por parte de las comunidades indígenas y afrodescendientes de Marmato, reconoce la relevancia constitucional de los modos de construcción social del territorio. Asimismo, lleva a cuestionar la validez de las decisiones estatales que, de manera paulatina, vienen borrando la frontera entre zona alta y baja de Marmato y, con ella, la forma de vida que define la identidad de sus habitantes.

\section{BIBLIOGRAFÍA}

Abad Salazar, Inés Lucía (1955). Los Ansermas. Tesis de Grado. Pontificia Universidad Católica Javeriana, Bogotá.

Aramburo Restrepo, José Luis (1980). Curso de Derecho Minero. Con una compilación de las disposiciones vigentes sobre la materia. Catolicismo, Bogotá.

Arias, Jorge Humberto y Gerardo Adarve (2004). Marmato, tierra de riqueza y esperanza. Presentación de power point (Fuente: archivo Comité Pro Defensa de Marmato).

BOBbio, NoRbERTo (1980). Sobre los criterios para resolver las antinomias. En: A. RUIZ MigueL (ed.). Contribución a la Teoría del Derecho. Fernando Torres Editor, Valencia, pp. 349-364.

Boussingault, Jean Baptiste (1994). Memorias 1823-1832, T. 2. República de Colombia, Presidencia de la República, Comisión Preparatoria para el V Centenario del Descubrimiento de América, Colcultura, Biblioteca Nacional de Colombia, Bogotá.

CARdona, F. (1939). Breves consideraciones acerca de la evolución de la propiedad minera en Colombia. En: Londoño OrTIZ, JoAQuín (1985). Estudio de la Legislación Minera Colombiana. Letras Cubanas, Medellín.

Defensoría del Pueblo (2010). La minería de hecho en Colombia. Informe Defensoría Delegada para los Derechos Colectivos y del Ambiente. Imprenta Nacional, Bogotá.

Departamento Nacional de Estadística, DANe (2005). Censo General de Población 2005 - Perfil Marmato (Caldas), disponible en: https://www.dane.gov.co/files/censo2005/perfiles/ caldas/marmato.pdf Última consulta: 23 de junio de 2012.

Fierro Morales, Julio (2012). Políticas mineras en Colombia. Bogotá, ILSA. 
Gallego Estrada, Alberto y Miguel Giraldo Rodas (s. f.). Historia de Marmato. Sin datos de edición.

García Villegas, Mauricio (1993). La eficacia simbólica del Derecho. Examen de situaciones colombianas. Universidad de los Andes, Bogotá.

Gärtner de la Cuesta, Carlos; Héctor Moreno díaz y Gabriel Sanín Villa (1936). Informe de la comisión de la Honorable Cámara de Representantes que visitó las minas de Supía y Marmato. Minería, año Iv, n. ⒋ Imprenta Oficial, Medellín, pp. 3258-3281.

GÄRTNER, JORGE (1939). Informe del Ministerio de la Economía Nacional. Imprenta Nacional, Bogotá

GÄRTNER, Álvaro (2005). Los místeres de las minas. Crónica de la colonia europea más grande de Colombia en el siglo XIX, surgida alrededor de las minas de Marmato, Supía y Riosucio. Universidad de Caldas, Manizales.

Giraldo Ramírez, Jorge y JuAn CARlos Muñoz Mora (2012). Informalidad e ilegalidad en la explotación del ORO y la MADERA en Antioquia. Proantioquia, Universidad EAFIT, Medellín.

GonZÁlez Colonia, CARlos Julio (2012). Brujería, minería tradicional y capitalismo transnacional en los Andes colombianos. El caso del pueblo minero de Marmato - Colombia. Tesis para optar al título de Magíster en Antropología Social del Instituto de Altos Estudios Sociales (IDAES) de la Universidad Nacional de San Martín (UNSAM), Buenos Aires.

GONZÁLEZ EsCOBAR, LUIS FERNANDO (2002). Ocupación, poblamiento y territorialidades en la Vega de Supía, 1810-1950. Ministerio de Cultura, Bogotá.

Lasso Lozano, Rosa Melina (2011). Campo de la minería del oro y habitus productivo en Marmato - Caldas: Estrategias de conservación y transformación en tiempos de globalización. Marmato - Caldas 2001-1011. Tesis para optar al título de Socióloga. Universidad de Caldas, Manizales.

Montañez Gómez, Gustavo (2001). Razón y pasión del espacio y el territorio. En: Red Espacio y Territorio (comp.). Espacio y territorios: razón, pasión e imaginarios. Universidad Nacional, Bogotá, pp. 15-32.

Morales Benítez, Отto (1993). Marmato en la perspectiva de la historia nacional. En: Teoría y aplicación de las historias locales y regionales. Disponible en: http://www. banrepcultural.org/blaavirtual/sociologia/histlocal/histlocal10a.htm\#124 Última consulta: 7 de julio de 2012 .

Poveda Ramos, Gabriel (2005). La minería colonial y republicana. Cinco siglos de variantes y desarrollos. En: Credencial Historia, 151.Disponible en: http://www.banrepcultural.org/ blaavirtual/revistas/credencial/julio2002/lamineria.htm Última consulta: 8 de julio de 2012.

RAMírez GuerRero, Mónica (2010). Territorio, minería y conflictos del desarrollo. Estudio de caso en el municipio de Marmato, Caldas. Informe de investigación para optar al título de Magíster en Desarrollo Regional y Planificación del Territorio. Universidad Autónoma de Manizales, Manizales. 
Restrepo, Vicente (1952). Estudio sobre las minas de oro y plata de Colombia (1885), 4. ed. Banco de la República, Bogotá.

Ross, Alf (1997). Sobre el Derecho y la Justicia (1953), trad. G. Carrió. Eudeba, Buenos Aires.

Sánchez Gómez, Gregorio (2010). La Bruja de las Minas (1938). Ministerio de Cultura, Biblioteca de Literatura Afrocolombiana, Bogotá.

Sandoval, Mary Luz y Rosa Melina Lasso (2012). Riesgo: teoría y realidad. El caso de Marmato, Caldas. En: Luna Azul, 34, enero-junio, pp. 170-194. Disponible en: http:// lunazul.ucaldas.edu.co/index.php?option $=$ com_content\&task=blogcategory \&id=14\&It emid=31 Última consulta: 29 de julio de 2012.

Segato, Rita Laura (2006). En busca de un léxico para teorizar la experiencia territorial contemporánea. En: D. Herrera Gómez y C. E. Piazzini (eds.). (Des)territorialidades y (No)lugares. Procesos de configuración y transformación social del espacio. Medellín, La Carreta, INER, Universidad de Antioquia, pp. 75-94.

TOBÓN RodRíGUEZ, MABEL (2000). Estudio de las condiciones físicas, sociales y económicas actuales del centro histórico de Marmato y su relación con el plan de ordenamiento territorial, para la elaboración de un Plan Especial de Protección”. Dirección de Patrimonio, Ministerio de Cultura, Bogotá.

WEBER, MAX (1997). Economía y sociedad. Esbozo de sociología comprensiva I (1922), trad. J. Medina EchaVARRía et. al. 1 a $^{\mathrm{a}}$ reimp. de la 2 . $^{\mathrm{a}}$ ed. en español, de la $4 .^{\text {a }}$ ed. en alemán. Fondo de Cultura Económica, Bogotá.

WeSt, RoBert C. (1972). La minería de aluvión en Colombia durante el período colonial, trad. J. O. Melo. Imprenta Nacional, Bogotá.

World Gold Council (2012). Interactive Goldprice chart and downloads. Disponible en: https:// www.gold.org/investment/statistics/gold_price_chart/ Última consulta: 8 de julio de 2012. 